\title{
Morphology-driven gas sensing by fabricated fractals: A review
}

\author{
Vishal Kamathe ${ }^{\ddagger}$ and Rupali Nagar ${ }^{*}, \neq$
}

\section{Review}

Address:

Nanomaterials for Energy Applications Lab, Applied Science

Department, Symbiosis Institute of Technology, Symbiosis

International (Deemed University), Lavale, Pune-412115,

Maharashtra, India

Email:

Rupali Nagar ${ }^{\star}$ - rupali.nagar@sitpune.edu.in

* Corresponding author $\ddagger$ Equal contributors

Keywords:

adsorption sites; fabricated fractal; fractal dimension; gas sensor;

morphology; pore network; recovery time; response time
Beilstein J. Nanotechnol. 2021, 12, 1187-1208.

https://doi.org/10.3762/bjnano.12.88

Received: 12 June 2021

Accepted: 22 October 2021

Published: 09 November 2021

Associate Editor: N. Motta

(C) 2021 Kamathe and Nagar; licensee Beilstein-Institut. License and terms: see end of document.

\begin{abstract}
Fractals are intriguing structures that repeat themselves at various length scales. Interestingly, fractals can also be fabricated artificially in labs under controlled growth environments and be explored for various applications. Such fractals have a repeating unit that spans in length from nano- to millimeter range. Fractals thus can be regarded as connectors that structurally bridge the gap between the nano- and the macroscopic worlds and have a hybrid structure of pores and repeating units. This article presents a comprehensive review on inorganic fabricated fractals (fab-fracs) synthesized in labs and employed as gas sensors across materials, morphologies, and gas analytes. The focus is to investigate the morphology-driven gas response of these fab-fracs and identify key parameters of fractal geometry in influencing gas response. Fab-fracs with roughened microstructure, pore-network connectivity, and fractal dimension $(D)$ less than 2 are projected to be possessing better gas sensing capabilities. Fab-fracs with these salient features will help in designing the commercial gas sensors with better performance.
\end{abstract}

\section{Introduction}

The industrial sector and its related activities have led to various forms of pollution that compounding up with time. One of the biggest challenges is to control air pollution as it directly affects the respiratory tract and may result in sudden fatalities. History has seen many unfortunate incidents due to the effusion of toxic vapors in the environment [1-4]. Such gas tragedies worldwide in the form of chemical leaks, smoke from fire accidents, and gas leaks from sewage systems, mines and industries, highlight the need of installing efficient gas sensors capable of detecting a range of flammable, poisonous, and harmful gases present in the atmosphere. Gas sensors are alerting systems that are installed in industry setups at both small and large scale, automobile, medical, agriculture, defense, commercial, and residential sectors and thus are versatile regarding their eventual usage 
[5-7]. The objectives in gas sensing research are usually set to enhance the sensitivity (how the sensor responds to small changes when the gas environment around it changes), selectivity (if a sensor can still respond to a particular gas when many gases present), stability (how the sensor responds in a particular environment with time), the response time (time taken by a sensor to detect no gas to $90 \%$ of the gas when exposed to a gas environment), and recovery time (time taken by a sensor to fall to $10 \%$ of its baseline resistance value when the gas is removed from the environment). Additionally, low cost, low power consumption, and simple fabrication of gas sensors are desirable factors. Different technologies have been used to detect numerous gases that include semiconductor, catalytic, electrochemical, optical, and acoustic gas sensors [8]. In particular, conductometric semiconductor metal oxide (SMO) sensors are most popular due to their low cost, simplicity, easy fabrication, and wide range of gas detection capabilities [9] Thin films and nanostructures exhibit better sensing characteristics. Various researchers have reported structures with morphologies such as nanowires (NWs) [10-16], nanorods [17-20], nanosheets [21-23], nanobelts [24,25], and nano/micro-spheres/ cubes/polyhedrons [26-29] with enhanced sensitivity as a gas sensor. A rich collection of research articles and review papers on distinct morphological nanostructured gas sensors exist $[26,30,31]$. Although there are numerous reviews on gas sensing [7,29,32-38], reviews on fabricated fractal (fab-frac)based gas sensors have not been addressed to the best of our knowledge. In this review, diverse fractal structures used in gas sensing applications are reviewed. The present article first describes what fractals are and what characteristic length scales are associated with fractal growth, followed by material-wise characterization of fab-frac gas sensors discussing their performance and fractal geometries. Some basic definitions are included to aid a non-specialist reader in the field of either fractals or gas sensing to comprehend the discussion. The article finally discusses the role of fractal geometry and identifies key parameters thereof in improving gas detection.

\section{Review}

\section{What are fractals?}

B. Mandelbrot, in 1975, coined the term fractal $[39,40]$. Figure 1 shows various fractal geometries found in nature. Complex patterns seen in human lungs, lines on the surface of human brains, neuron distribution, molecular chains of proteins, and DNA structures with double helix are described by fractal geometries [41]. Ice crystals, lightnings during thunder storms, mountain ranges, and canyons, among many inanimate objects, and some classical patterns such as Koch curves, Cantor sets, and Sierpinski triangles in geometry are also characterized by fractal geometries [41]. These complex, never-ending, replicating patterns across different length scales are termed as frac- tals. Few researchers have reported fractal growth under lab environment [40,42-45], which are artificially made and are referred to as fab-fracs in this work.
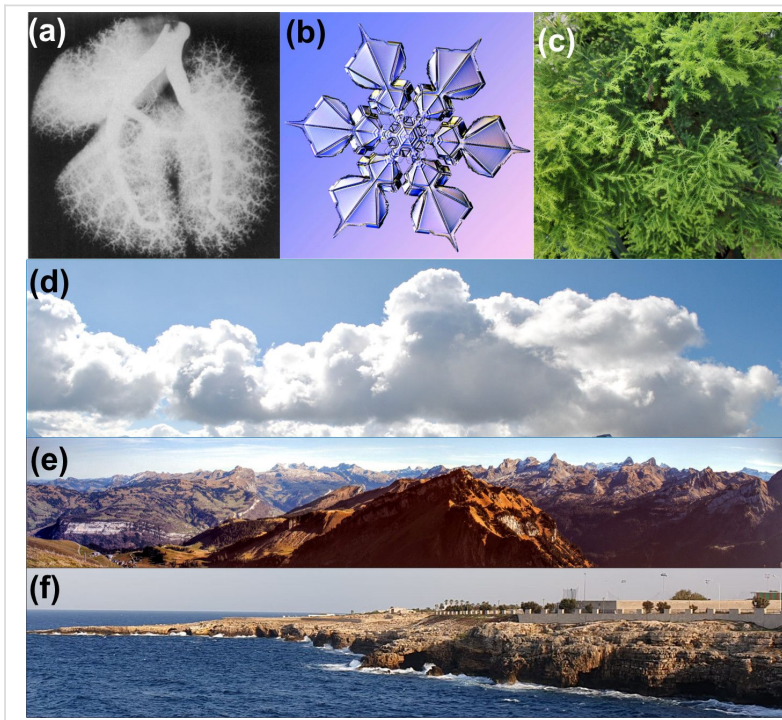

Figure 1: Fractals in nature. Various fractal geometries found in nature: (a) human lung network, (b) snowflakes, (c) leaves, (d) clouds, (e) mountain peaks, and (f) coastline. Image credits: Figure 1a was reproduced from [46], Mary I. Townsley, "Structure and composition of pulmonary arteries, capillaries and veins", Comprehensive Physiology, with permission from John Wiley \& Sons. Copyright (C) 2012 American Physiological Society. All rights reserved. This content is not subject to CC BY 4.0. Figure 1b was reproduced with permission from [47], SnowCrystals.com by Prof. Kenneth G. Libbrecht. This content is not subject to CC BY 4.0 .

\section{Fractal length scales and growth models}

All fractal geometries have characteristic length scales, namely fractal dimension $(D)$, lacunarity $(L)$, and connectivity $(Q)$, that describe geometric features. Figure 2a shows the examples of different fractal clusters with varying values of $D$ and $L$ [48]. While $D$ measures the complexity of a system, $L$ measures the morphological inhomogeneity of fractals. The number $L$ also characterizes fractal textures and quantifies the fractal-to-fractal gaps; the higher the lacunarity, the lower is the homogeneity [49]. In fractal studies, surface morphology, geometrical features, and degree of self-organization of materials are determined through these dimensionless numbers [50]. One of the most popular methods employed for determining fractal dimensions is the box-counting method. In this, $N$ square grids each of edge length $\ell$ are placed over an actual optical image or scanning electron micrograph (SEM) with the help of image analysis software. The fractal dimension $D$ is then estimated by $[43,51]$ :

$$
D=\frac{\ln (N)}{\ln (1 / \ell)} .
$$


This analysis also predicts the power law governing the growth within the fractal space. Growth of fractals in unique geometrical patterns has been predominantly a subject of theoretical treatment. The diffusion-limited aggregation (DLA) model was proposed in 1981 by applying it to the random movement of a metallic ion in a low concentration of electrolyte near a negatively charged electrode [52]. The process resulted in a tree-like scale-invariant structure [52,53]. Figure $2 b$ demonstrates the growth mechanism of a fractal proposed by DLA. Theories of non-equilibrium processes predict pattern formation by considering movement/diffusion of aggregates that ultimately results

(a)

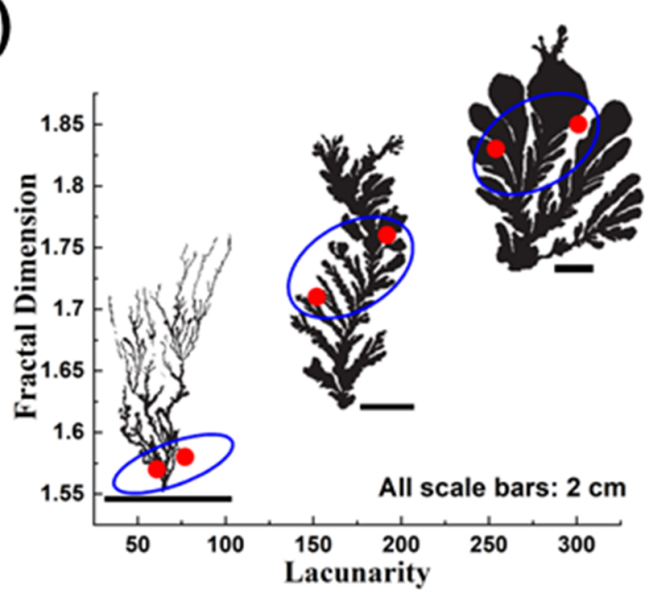

(b)

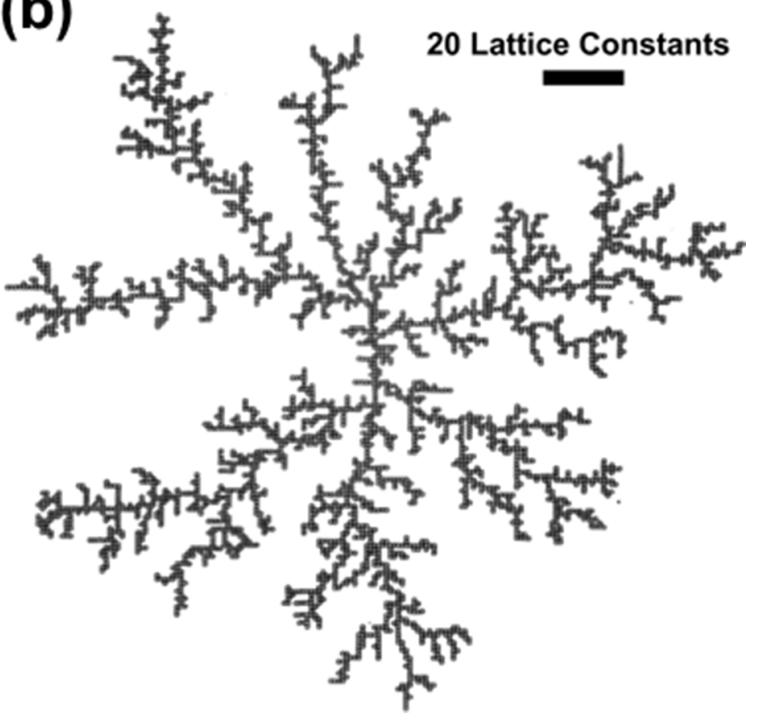

Figure 2: (a) Fractal morphology. Fractal length scales depicting the change in fractal geometry as a function of the fractal dimensions $D$ and $L$. Figure 2a was adapted with permission from [48], (C) 2009 Geological Society of Malaysia. This content is not subject to CC BY 4.0 (b) Diffusion-limited aggregation. Random aggregate of 3600 particles on a square lattice. Figure $2 \mathrm{~b}$ was reprinted with permission from [52] (T. A. Witten Jr; L. M. Sander, Physical Review Lett., vol. 47, page $1400,1981)$. Copyright (1981) by the American Physical Society. This content is not subject to CC BY 4.0. in the final fractal pattern $[53,54]$. In the DLA model, one seed particle is placed initially at a location called "origin" of a chosen lattice. Then, another particle is placed far from this origin location. The second particle diffuses via random walk, reaches a site close to the seed particle, and subsequently comes to a stop. In a similar way, other particles are added one by one and allowed to move randomly or guided by diffusion [54]. The added particles eventually reach their final sites and come to rest. The formation of large clusters is thus explained by DLA [52-54]. Like nano/micromaterials, fabricated fractals too, show enhanced sensing abilities due to high porosity (size, number, and pore interconnectivity) and surface area, and high physical connectivity within branched objects $[49,55,56]$. Figure 3 shows different morphologies of large-scale $\mathrm{SnO}_{2}$ fab-fracs grown under controlled lab conditions. The study of the specific surface becomes important for understanding the growth of such structures and investigating the gas sensor characteristics when such structures are used as sensing material [57].

\section{Proposed growth model for fab-fracs}

This section specifically discusses the various parameters that influence the final shape of a lab-grown fab-frac using the sol-gel technique. Nucleation is a random and probabilistic event that happens on a substrate. As a fluid starts drying, evaporation of the solvent causes voids and helps in generating clusters of the solute on the substrate. For smaller pockets of the fluid, which can be regarded as droplets, variation in surface tension or temperature at different interfaces predominantly causes either a surface tension gradient or a thermal gradient. The diffusivity and dynamic viscosity affect the way in which mass is transported on the substrate. These gradients cause a circulatory flow of fluid, influence the mass transport, and eventually result in differently patterned fractal structures. The effects are, respectively, termed as Gibbs-Marangoni concerning surface tension gradients and Bénard-Marangoni concerning thermal gradients [58-62]. The pattern and shape of the fractals depend on flux, thermal energy, surface energy, and diffusion coefficient of the clusters. The schematic shown in Figure 4 depicts the different stages of fractal formation and conditions that lead to a specific fractal shape. Initially, when the sol starts drying, voids are created due to effusion of gases from the sol. Thereafter, random nucleation and cluster growth takes place. After clusters form on the substrate, further growth into specific fractal shapes depends mainly on availability of sol flux near the growing cluster and the Marangoni effect that includes both thermal energy and diffusion aspects. With limited flux but lower diffusion, rhombohedral fractals are formed that are sparsely spaced on the substrate while with higher diffusion the rhombohedra get very close to assuming a cruciform shape. In the case of high flux and high diffusion, interconnections form on the substrate over a larger scale result- 

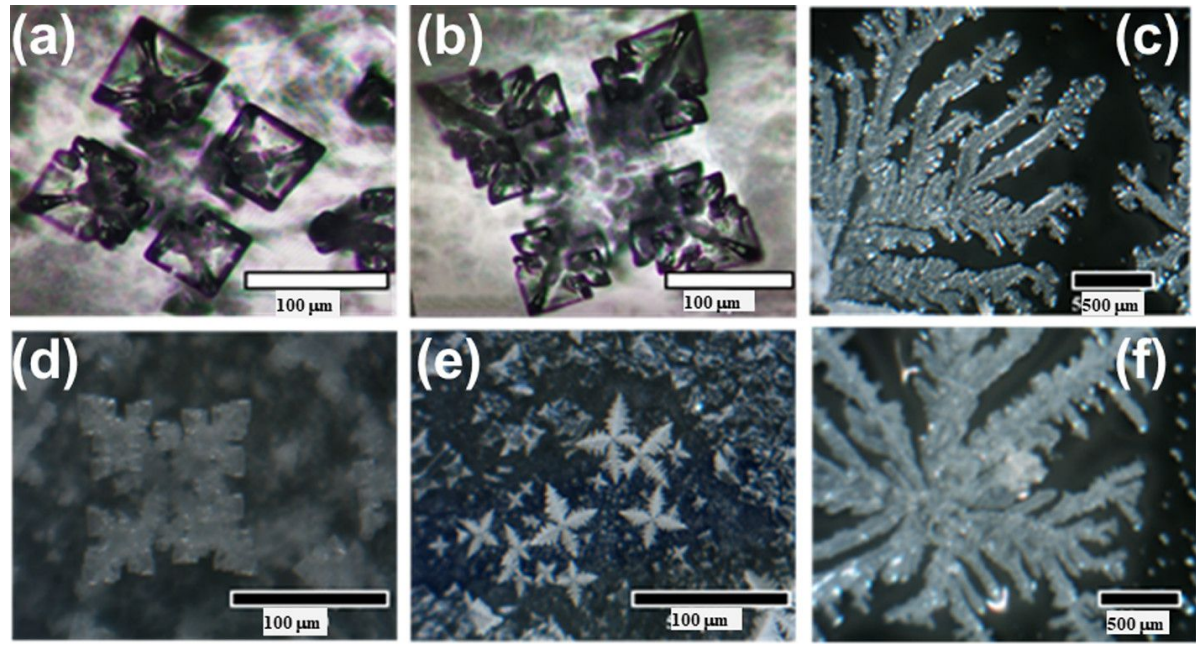

Figure 3: $\mathrm{SnO}_{2}$ fab-fracs. Various shapes of large-scale $\mathrm{SnO}_{2}$ fab-fracs synthesized under controlled conditions in a lab environment.

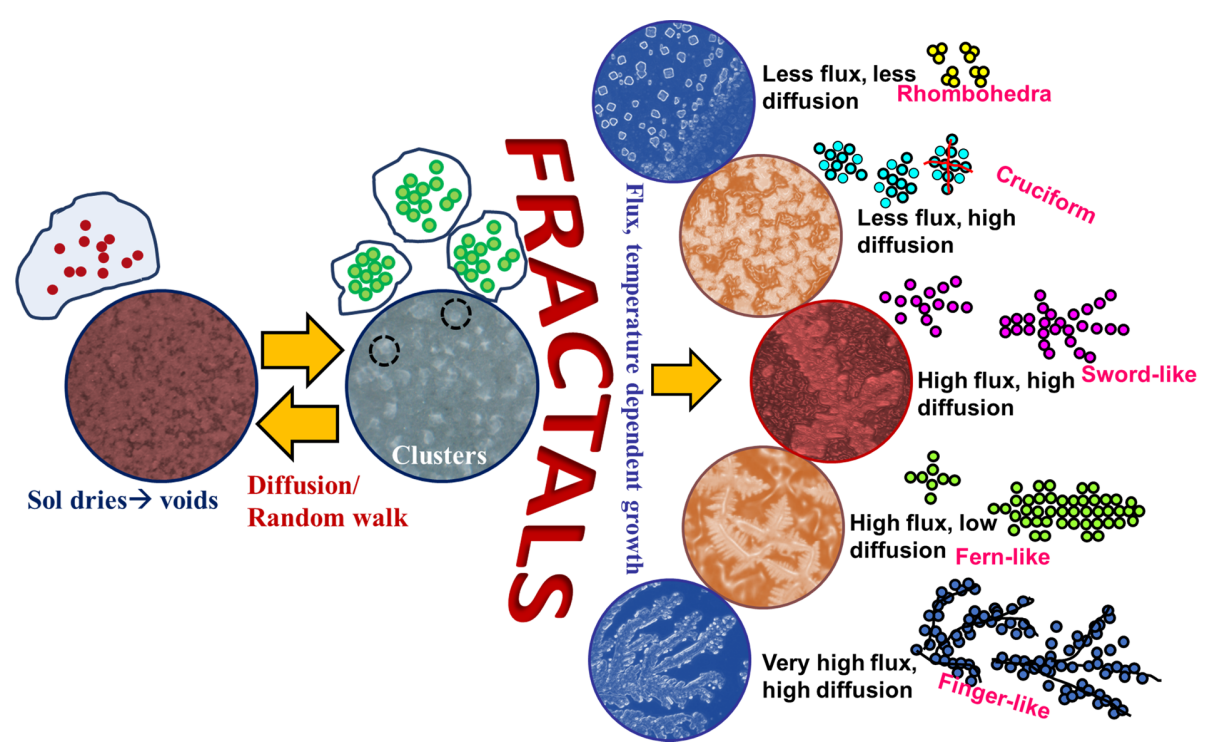

Figure 4: Growth of sol-gel-grown fab-fracs. The schematic depicts the growth mechanism of fab-fracs in different geometries.

ing in longer sword-like fractals. When high flux is available, but diffusion is limited, fractals take the shape of fern-like dendrites. Lastly, with very high flux and high diffusion rates macroscale fractals are obtained. These phenomena are explained in Figure 4 and corresponding optical images of fabfracs grown in the lab are shown.

\section{Fractal structures as gas sensors}

The complex fractal geometries offer many reasons to be tested for sensing applications. This section reviews the formation of fab-fracs, sorted by the material of the structures, and their performance in gas sensing applications by comparing the fractal dimension, $D$. Wherever the fractal dimension has not been re- ported, these were estimated using image analysis software. Nano/microscale spheres, cubes, or polyhedra have been applied also as gas sensors. However, these geometries are not discussed in detail in this article due to absence of repeated growth units at different length scales. The interested readers are directed to some excellent articles on hierarchical gas sensors that address such geometries [8,30,33,37].

\section{Tin oxide-based fractals}

Yin et al. reported $\mathrm{SnO}_{2}$ nanoparticles with and without platinum $(\mathrm{Pt})$ decoration synthesized using a sol-gel hydrothermal technique for gas sensing applications [63]. Figure 5a,b shows SEM images of samples calcined at $550{ }^{\circ} \mathrm{C}$, corresponding to 

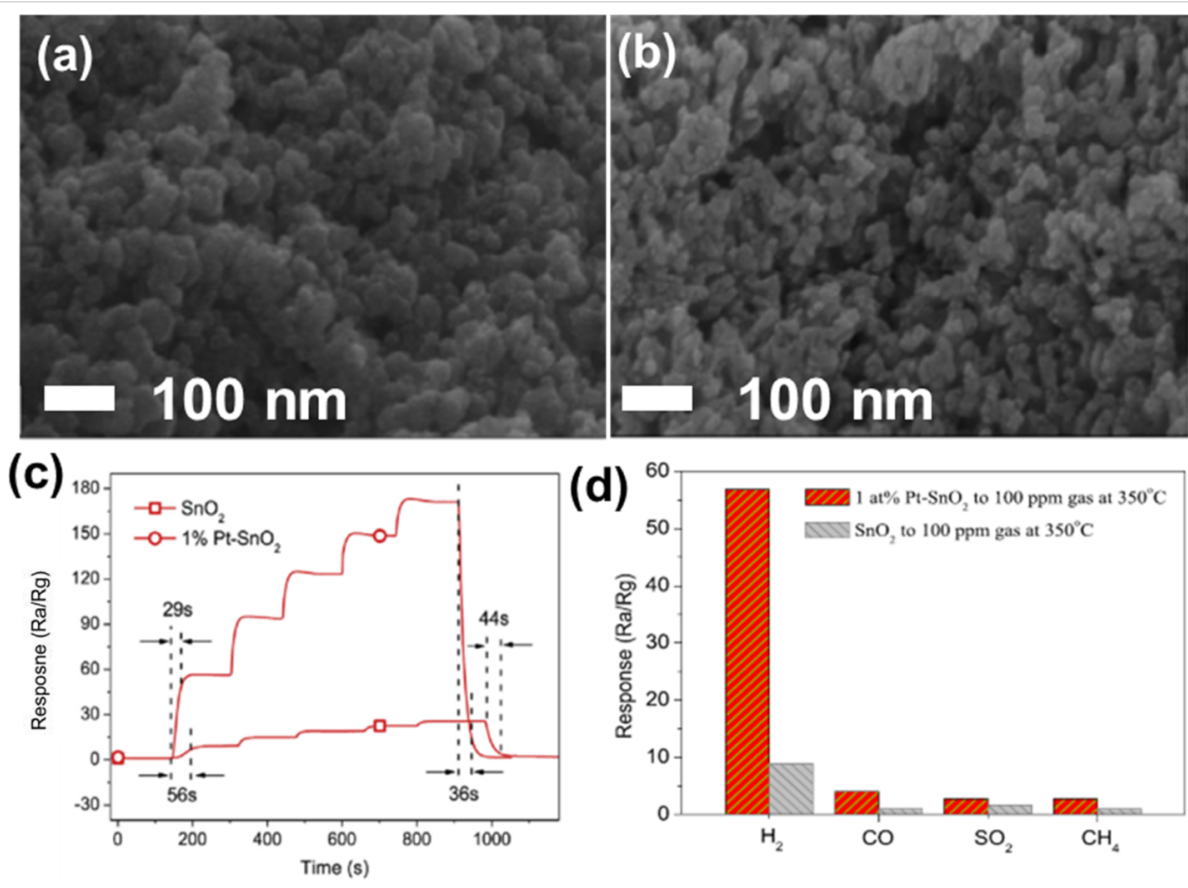

Figure 5: $\mathrm{SnO}_{2}$ fractals for $\mathrm{H}_{2}$ sensing. SEM images of samples calcined at $550{ }^{\circ} \mathrm{C}$ displaying a microstructure of (a) $\mathrm{SnO} \mathrm{O}_{2}$ and (b) 1 atom $\%$ $\mathrm{Pt}_{-} \mathrm{SnO}_{2}$. (c) Response curve of 1 atom \% $\mathrm{Pt}_{-} \mathrm{SnO}_{2}$ for $\mathrm{H}_{2} \mathrm{ppm}$ level concentrations at $350{ }^{\circ} \mathrm{C}$. (d) Gas sensor selectivity towards 100 ppm of gases/vapors of $\mathrm{H}_{2}$ against $\mathrm{CO}, \mathrm{SO}_{2}$, and $\mathrm{CH}_{4}$ at $350{ }^{\circ} \mathrm{C}$. Figure $5 \mathrm{a}-\mathrm{d}$ was reprinted from [63], Journal of Alloys and Compounds, vol. 805, by $\mathrm{X}$.- $\mathrm{T}$. Yin; W.-D. Zhou; J. Li; Q. Wang; F.-Y. Wu; D. Dastan; D. Wang; H. Garmestani; X.-M. Wang; Ş. Țălud, "A highly sensitivity and selectivity Pt-SnO 2 nanoparticles for sensing applications at extremely low level hydrogen gas detection", pages no. 229-236, Copyright (2019), with permission from Elsevier. This content is not subject to CC BY 4.0 .

pure $\mathrm{SnO}_{2}$ and $\mathrm{Pt}-\mathrm{SnO}_{2}$, respectively. The box-counting method estimated $D=2.43$ for pure $\mathrm{SnO}_{2}$ and 2.49 for $\mathrm{SnO}_{2}$ decorated with $1 \mathrm{wt} \% \mathrm{Pt}$, respectively. Figure $5 \mathrm{c}$ shows the $\mathrm{H}_{2}$ sensing response curve of 1 atom $\% \mathrm{Pt}-\mathrm{SnO}_{2}$. In comparison to pure $\mathrm{SnO}_{2}$ and different amounts of $\mathrm{Pt}$ decoration (viz. 0.2, 0.5, 1 , and 2 atom \%), the 1 atom \% Pt-decorated $\mathrm{SnO}_{2}\left(\mathrm{Pt}-\mathrm{SnO}_{2}\right)$ sample exhibited higher sensitivity, a faster response of $29 \mathrm{~s}$ at $350{ }^{\circ} \mathrm{C}$, and was able to sense $0.08 \mathrm{ppm}_{2}$. The sensor response was highest for $\mathrm{H}_{2}$ as compared to $\mathrm{CO}, \mathrm{CH}_{4}, \mathrm{NO}_{2}$ and $\mathrm{SO}_{2}$ gases at $100 \mathrm{ppm}$ gas at 350 degree centigrade. Though the morphology of the fractals did not change appreciably, Pt doping led to faster response and recovery times. This could be due to the excellent interaction of Pt with hydrogen via the established spillover effect that catalyzes hydrogen adsorption [64,65]. Figure 5d depicts the response of fab-fracs with $D=2.43$ and 2.49 for different gases. Pt decoration can be seen to improve the sensing performance for all analyte vapors, and this can be attributed to the higher catalytic activity due to Pt $5 \mathrm{~d}$ electrons and the fractal geometry.

Plugotarenko et al. employed sol-gel method to prepare $\mathrm{SiO}_{2} \cdot \mathrm{SnO}_{x} \cdot \mathrm{CuO}_{y}$ nanofilms from a tetraethoxysilane (TEOS) alcohol solution modified by metal salts and applied the samples for $\mathrm{NO}_{2}$ sensing [50]. The $\mathrm{SiO}_{2} \cdot \mathrm{SnO}_{x} \cdot \mathrm{CuO}_{y}$ films annealed at $500{ }^{\circ} \mathrm{C}$ exhibited a sample surface consisting of crater-like pits. The self-organization of structures was attributed to tin chloride, which led to a larger size of the pits, while copper oxide led to the formation of hillocks in the film. The $D$ values of the samples were in the range of 2.00-2.24. For the $\mathrm{Sn} / \mathrm{Cu}=6$ ratio, the fractal dimension was 2.0 , and the sample, exhibiting a combination of hillocks and pores, showed the maximum sensitivity $(S=0.29)$ towards $\mathrm{NO}_{2}$. Another study reported dendritic nanowires (DNWs) of $\mathrm{SnO}_{2}$ on a gold-coated silicon substrate for $\mathrm{NO}_{2}$ sensing [66]. The samples were prepared by evaporation-condensation. Figure $6 \mathrm{a}$ and Figure $6 \mathrm{~b}$ show low- and high-magnification SEM images of $\mathrm{SnO}_{2}$ DNWs, respectively. The sensitivity of $\mathrm{SnO}_{2}$ DNWs at different temperatures and concentrations of $\mathrm{NO}_{2}$ gas is shown in Figure $6 c$. The sensors exhibited the best performance at $200{ }^{\circ} \mathrm{C}$, at which it was found that the resident oxygen on the sensor surface had minimum influence. Thus, better interaction between $\mathrm{NO}_{2}$ and the sensor surface was achieved. The $\mathrm{SnO}_{2}$ DNWs were estimated to have a fractal dimension of 1.82 .

In 2017, Zang et al. fabricated $\mathrm{SnO}_{2}$ leaf-like hierarchical structures by hydrothermal synthesis [67]. Figure 7a-f shows SEM images of $\mathrm{SnO}_{2}$ structures after different reaction times. Figure $7 \mathrm{~g}$ shows a schematic of the formation of hierarchical $\mathrm{SnO}_{2}$ structures. Figure $7 \mathrm{~h}-\mathrm{j}$ illustrate the response curves as 

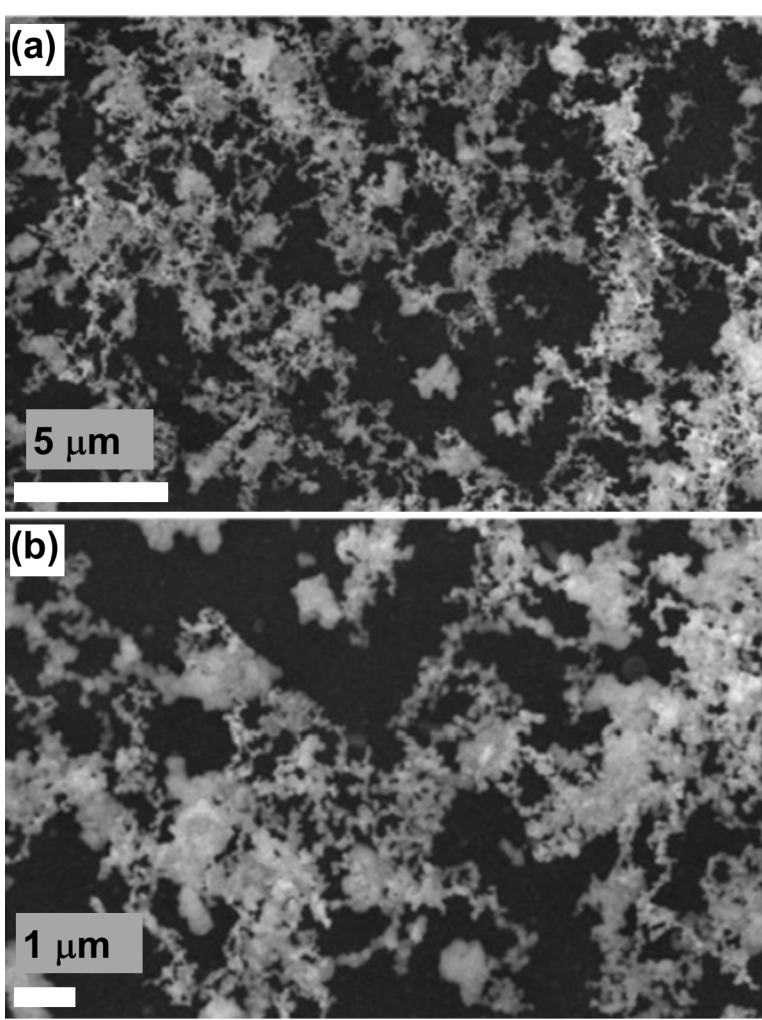

(c)

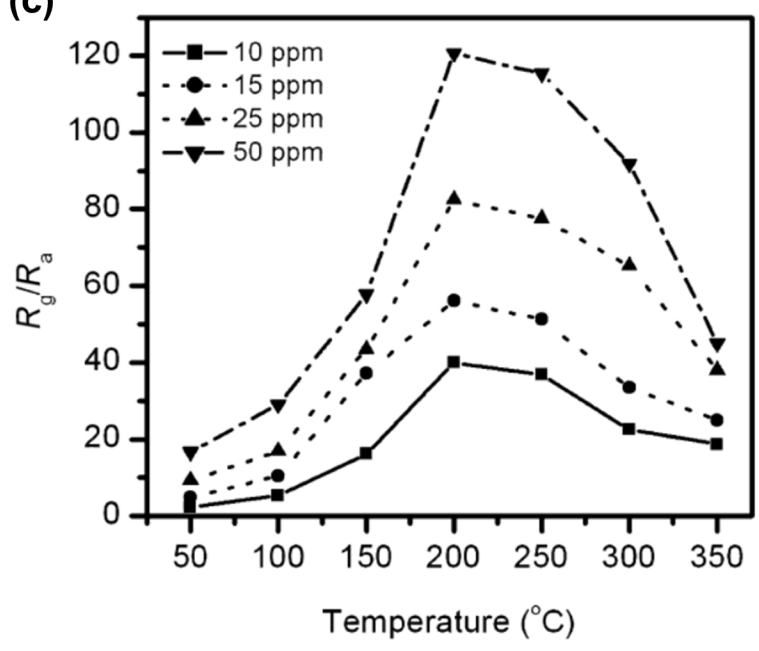

Figure 6: $\mathrm{SnO}_{2}$ dendritic nanowires. $\mathrm{SEM}$ images of $\mathrm{SnO}_{2} \mathrm{DNWs}$ at low (a) and high (b) magnifications, respectively. (c) The sensitivity versus temperature curve for $10-50 \mathrm{ppm} \mathrm{NO}$. Figure $6 \mathrm{a}-\mathrm{c}$ was reprinted from [66], Journal of Alloys and Compounds, vol. 510, by S.H. Mohamed, " $\mathrm{SnO}_{2}$ dendrites-nanowires for optoelectronic and gas sensing applications", pages no. 119-124, Copyright (2012), with permission from Elsevier. This content is not subject to CC BY 4.0.

function of the temperature (Figure $7 \mathrm{~h}$ ), of the time at $65^{\circ} \mathrm{C}$ to $500 \mathrm{ppb} \mathrm{NO}_{2}$ exposure (Figure 7i), and of the $\mathrm{NO}_{2}$ concentration (Figure 7j). The dendritic leaf-like structures provided active sites for the chemical reactions occurring on the surface. Figure $7 \mathrm{k}$ and Figure 71 show, respectively, the response of a leaf-like $\mathrm{SnO}_{2}$ architecture to different gases and its stability against $\mathrm{NO}_{2}$. The fab-frac structure demonstrated enhanced sensing response and better selectivity to $\mathrm{NO}_{2}$ at $65^{\circ} \mathrm{C}$. These sensing characteristics were attributed to the dendritic structure promoting diffusion and increasing the availability of adsorption sites. The structures were estimated to have a fractal dimension of 1.78. The results of these three studies show that a lower value of fractal dimension is more effective in sensing $\mathrm{NO}_{2}$ gas and lowers the optimum operating temperature.

Chen et al. used pulsed laser deposition for growing different $\mathrm{SnO}_{2}$ thin films by varying the substrate temperature. The obtained films exhibited fractal features [43]. In another study, Kante et al. prepared $\mathrm{SnO}_{2}$ films with fractal morphology by an electrochemical method with a subsequent oxidation process [68]. Both groups tested the films for CO gas sensing at different temperatures. Figure 8a-d shows the SEM images of $\mathrm{SnO}_{2}$ thin films on a $\mathrm{Si}(100)$ substrate obtained by Chen and co-workers. Figure 8e shows the CO sensing behavior of the fabricated films in the temperature range of $300-450{ }^{\circ} \mathrm{C}$. Figure $8 \mathrm{f}$ and Figure $8 \mathrm{~g}$ show the values of $D$ and fractal density as functions of the temperature. The authors concluded that the sensitivity to $\mathrm{CO}$ was mainly influenced by channel interconnections, fractal dimension, density, and average size of the fractal clusters. A sensitivity of 0.8 at $450{ }^{\circ} \mathrm{C}$ for $500 \mathrm{ppm}$ of $\mathrm{CO}$ was achieved. Lower fractal dimension $(D=1.818$ at $450{ }^{\circ} \mathrm{C}$ ) and density favored a higher sensitivity towards $\mathrm{CO}$. This could be due to the increased porosity of the structures resulting in more interaction sites at which analyte and sensor can interact. The authors termed the mechanism "random tunneling junction network". Here, electron transport across the fractal structures is assumed to occur via tunneling. Different fractal dimensions lead to different Schottky barrier heights across the film surface with few locations having a small barrier height depending upon fractal dimension and geometry. Such locations serve as sites with improved sensitivity and respond to the gas faster than other locations that have higher Schottky barrier heights. The gas sensing measurements performed by Kante et al. were in the temperature range of $200-300{ }^{\circ} \mathrm{C}$. For CO, the response was observed to be about 2.5 at $250{ }^{\circ} \mathrm{C}$ with a response time of $70 \mathrm{~s}$ and a recovery time of $30 \mathrm{~s}$. When exposed to ethanol vapor, the resulting film exhibited a higher sensitivity $\left(400 \%\right.$ at $\left.227^{\circ} \mathrm{C}\right)$ towards ethanol with a response time of $140 \mathrm{~s}$. The fractal dimensions of the investigated samples ranged from 1.4 to 1.6. The authors did not observe any dependence on $D$, but a dependence on grain size was reported. These results indicate that a fractal geometry alone is not sufficient to gain better gas sensitivity. Gracheva and co-workers prepared gas-sensitive fractal structures based on $\mathrm{SnO}_{2}$ and silicon dioxide $\left(\mathrm{SiO}_{2}\right)$ by a sol-gel technique $[57,69,70]$. The evolution of fractal aggregates of tin and silicon dioxides 

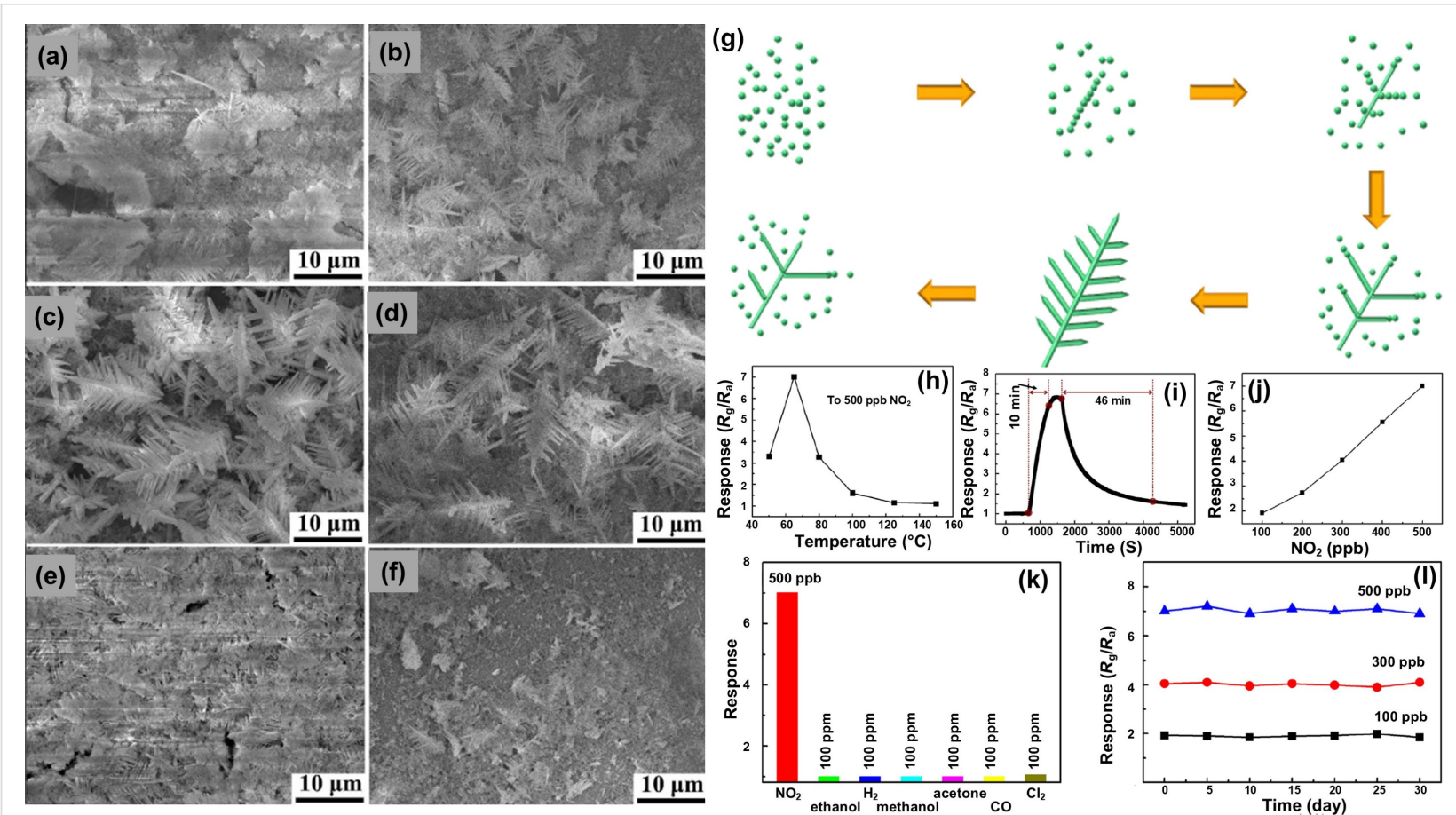

Figure 7: Leaf-like $\mathrm{SnO}_{2}$. (a-f) $\mathrm{SnO}_{2}$ SEM images of samples obtained after different reaction times, (g) schematic showing the formation of $\mathrm{SnO} 2$ structures, (h) sensor response at different temperatures, (i) dynamic response curve of the sensor for $500 \mathrm{ppb} \mathrm{NO}_{2}$ obtained at $65^{\circ} \mathrm{C}$, (j) sensor response to varying $\mathrm{NO}_{2}$ concentrations, (k) response to various gases and (I) stability of the sensor at different concentrations of $\mathrm{NO}_{2}$. Figure $7 \mathrm{a}-\mathrm{I}$ was reprinted from [67], Sensors and Actuators B: Chemical, vol. 255, by Y. Zhang; D. Li; L. Qin; P. Zhao; F. Liu; X. Chuai; P. Sun; X. Liang; Y. Gao; Y. Sun, "Preparation and gas sensing properties of hierarchical leaf-like $\mathrm{SnO}_{2}$ materials", pages no. 2944-2951, Copyright (2018), with permission from Elsevier. This content is not subject to CC BY 4.0 .

resulted in the formation of spherical, labyrinth, and percolation network structures. The spherical and labyrinth structures exhibited low sensitivity to ethanol and acetone vapors, while a sensitivity greater than 20 it was observed in case of percolation network nanostructures. Thus, the network and pore connectivity of fractal nanostructures becomes crucial for a better gas sensing response. Similar observations on the importance of network interconnectivity have been made by Chen et al. as discussed above.

In 2011, Phadungdhitidhada et al. prepared $\mathrm{SnO}_{2} \mathrm{NWs}$ of different diameters (from 50-150 nm) with and without nanodendrites (NDs), with lengths extending to a few tens of micrometers and NDs of 100-300 $\mathrm{nm}$ in diameter by closed crucible carbothermal reduction of $\mathrm{SnO}_{2}$ [71]. Figure 9a and Figure 9b show SEM micrographs of the synthesized $\mathrm{SnO}_{2}$ structures at lower and higher magnification, respectively. Figure $9 \mathrm{c}$ illustrates the sensor response at different temperatures for different concentrations of ethanol. The $\mathrm{SnO}_{2}$ with NDs showed enhanced ethanol sensing in comparison to $\mathrm{SnO}_{2} \mathrm{NWs}$ without NDs, which was attributed to a higher surface-to-volume ratio, more grain boundaries, and the presence of junction barriers at the ND-NW interfaces. The estimated $D$ for the $\mathrm{SnO}_{2}$ nanodendrites was 1.88 .
$3 \mathrm{D}$ porous nanoscale hybrid $\mathrm{SnO}_{2} / \mathrm{CuO}$ foam sensors were prepared by Jeun et al. via electrochemical deposition followed by thermal oxidation [72]. These foam sensors were studied for $\mathrm{H}_{2} \mathrm{~S}$ gas sensing. Figure 10a and Figure 10b show SEM images of the porous and 3D network structure of as-prepared $\mathrm{Sn} / \mathrm{Cu}$ foam after electrodeposition. Figure 10c and Figure 10d illustrate the porous foam structure formed at $700{ }^{\circ} \mathrm{C}$ by thermal oxidation and the dendritic structures formed in pore wall. The foam sensor was able to detect down to $4 \mathrm{ppm}$ of $\mathrm{H}_{2} \mathrm{~S}$. The highest gas response $(S=576)$ was obtained for $20 \mathrm{ppm}$ of $\mathrm{H}_{2} \mathrm{~S}$ at $250{ }^{\circ} \mathrm{C}$. The study shows that the $\mathrm{SnO}_{2} / \mathrm{CuO}$ nanoscale hybrid foam sensor outperforms the porous $3 \mathrm{D}$ network structure, mainly due to larger surface area, the formation of $\mathrm{p}-\mathrm{n}$ junctions, and the sulfurization of $\mathrm{CuO}$ on metallic conductors. The foam sensor also showed a response to $20 \mathrm{ppm}$ of hydrogen, carbon monoxide, ammonia, nitrous oxide, and ethanol (Figure 10e,f) at $250{ }^{\circ} \mathrm{C}$. The estimated fractal dimensions were 1.82 for the pore network and 1.72 for the foam sensor.

\section{Titanium oxide-based fractals}

Fusco et al. modified dielectric titanium oxide $\left(\mathrm{TiO}_{2}\right)$ nanoparticles with fractal structure with a plasmonic gold $(\mathrm{Au})$ metasurface for sensing volatile organic compounds (VOCs) [49]. This modification enhanced the plasmonic field and local surface 

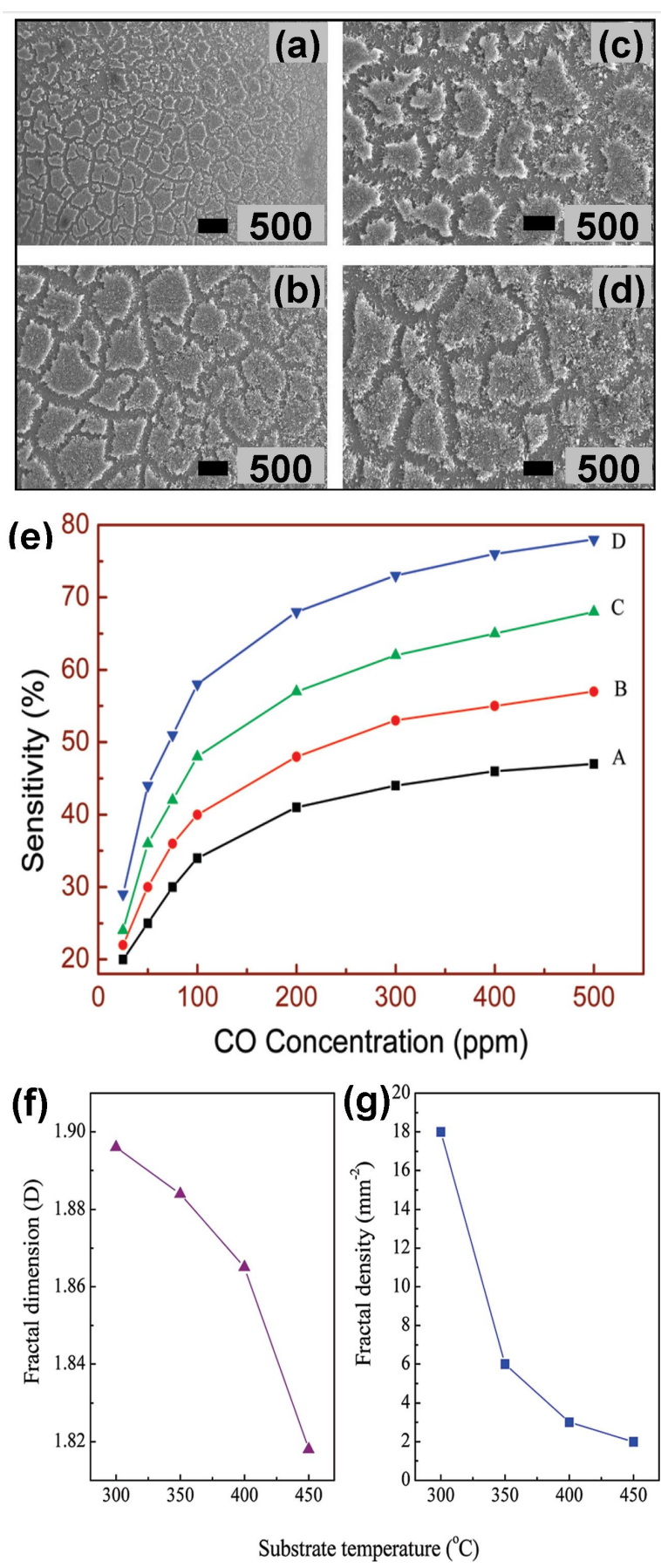

Figure 8: Density and dimension of $\mathrm{SnO}_{2}$ fractal films. (a-d) SEM images and (e) $\mathrm{CO}$ gas sensing behavior of $\mathrm{SnO}_{2}$ thin films prepared on $\mathrm{Si}(100)$ substrate at different temperatures $\left(\mathrm{A}: 300^{\circ} \mathrm{C}, \mathrm{B}: 350^{\circ} \mathrm{C}\right.$, C: $400^{\circ} \mathrm{C}, \mathrm{D}: 450^{\circ} \mathrm{C}$ ). (f, g) Influence of the temperature on $D$ and fractal density. Figure 8a-g was reproduced with permission from [43], Copyright 2010 American Chemical Society. This content is not subject to CC BY 4.0.

plasmonic resonance (LSPR). The influence of the gold nanodisk diameter and the average thickness of the $\mathrm{TiO}_{2}$ fractal on LSPR sensing of VOCs, specifically ethanol, acetone, and toluene, was examined. The LSPR sensor showed a 4-8 times
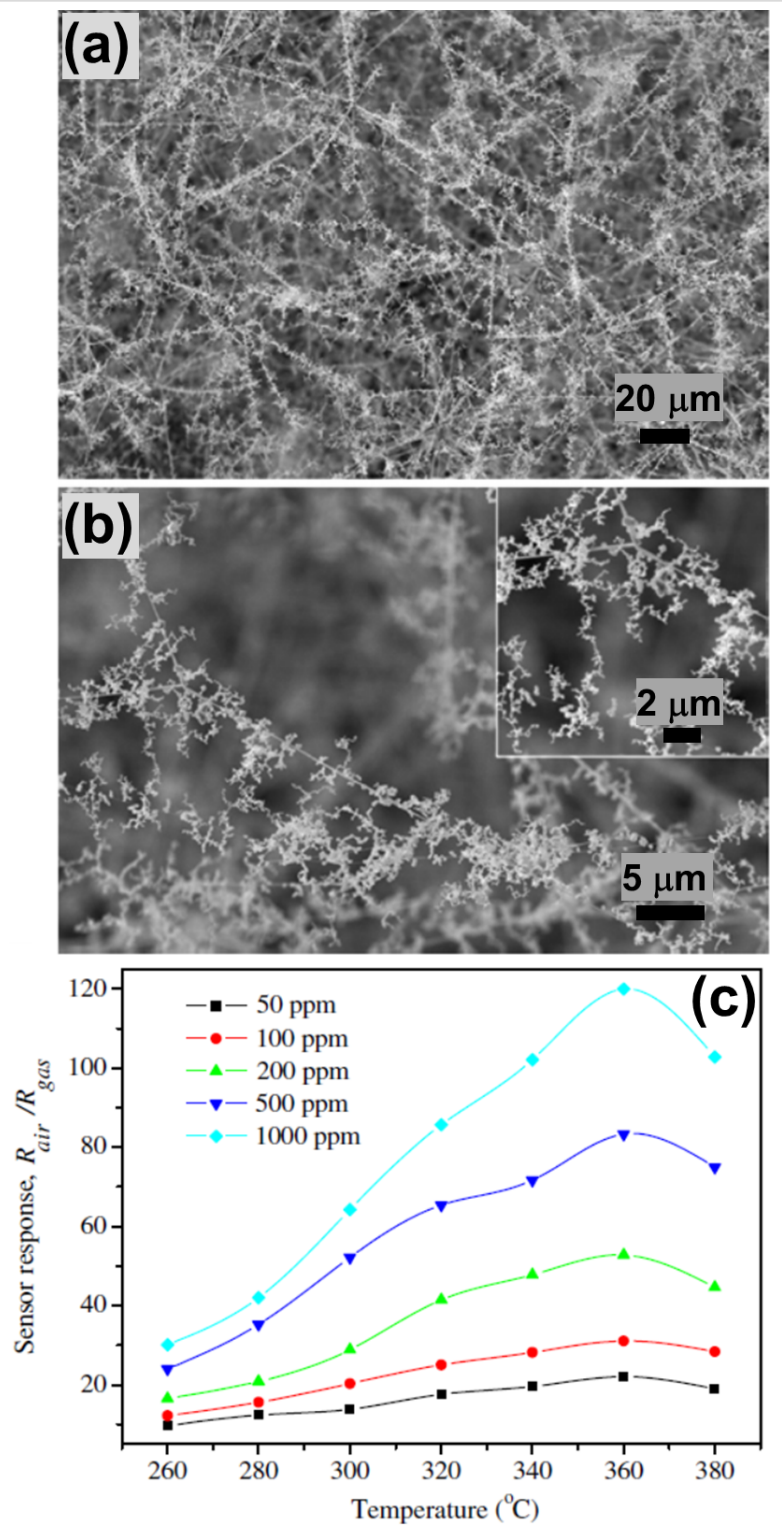

Figure 9: $\mathrm{SnO}_{2}$ fractal ethanol sensors. Typical SEM images with (a) low and (b) high magnification of the grown $\mathrm{SnO}_{2}$ nanostructures (insets show linkages of nanodendrites). (c) The sensor response as function of the temperature with different $\mathrm{C}_{2} \mathrm{H}_{5} \mathrm{OH}$ concentrations. Figure 9a-c was reprinted from [71], Current Applied Physics, vol. 11, by S. Phadungdhitidhada; S. Thanasanvorakun; P. Mangkorntong; S. Choopun; N. Mangkorntong; D. Wongratanaphisan, " $\mathrm{SnO}_{2}$ nanowires mixed nanodendrites for high ethanol sensor response", pages no. 1368-1373, Copyright (2011), with permission from Elsevier. This content is not subject to CC BY 4.0 .

higher sensitivity for detecting gas molecules with the fractalenhanced dielectric structure. The enhancement in the sensitivity was mainly attributed to the large surface-to-volume ratio of fractal system, which resulted in a higher probability of volatile gases condensing, and the enhancement of the electrodynamic field above the Au surface. These factors were vital only up to certain thickness above which it was believed that the volatile gases penetrate into the fractal volume followed by diffu- 

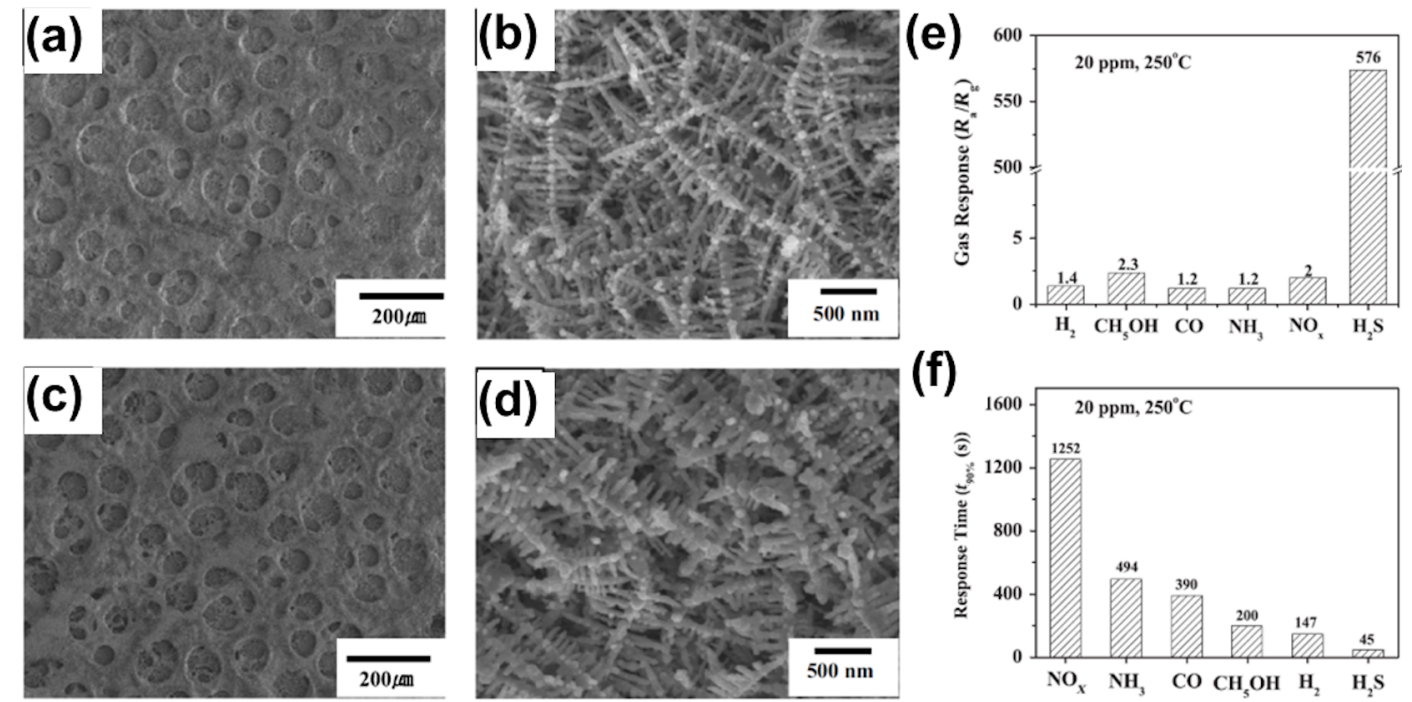

Figure 10: $\mathrm{SnO}_{2} / \mathrm{CuO}$ nanoscale hybrid dendrites. SEM images of (a) $\mathrm{Sn}-\mathrm{Cu}$ porous foams, (b) the 3D interlock network structure of the as-deposited sample, (c) oxide foam annealed at $700{ }^{\circ} \mathrm{C}$, and (d) the structure of dendrites formed in the pore wall at $700{ }^{\circ} \mathrm{C}$. (e) Gas response and (f) response time of the $\mathrm{SnO}_{2} / \mathrm{CuO}$ nanoscale hybrid foam sensor to $20 \mathrm{ppm}$ of $\mathrm{H}_{2}, \mathrm{C}_{2} \mathrm{H}_{5} \mathrm{OH}, \mathrm{CO}, \mathrm{NH}_{3}, \mathrm{NO}_{x}$, and $\mathrm{H}_{2} \mathrm{~S}$ at $250{ }^{\circ} \mathrm{C}$. Figure $10 \mathrm{a}-\mathrm{f}$ was reprinted from [72], Materials Letters, vol. 105, by J.-H. Jeun; D.-H. Kim; S.-H. Hong, " $\mathrm{SnO}_{2} / \mathrm{CuO}$ nano-hybrid foams synthesized by electrochemical deposition and their gas sensing properties", pages no. 58-61, Copyright (2013), with permission from Elsevier. This content is not subject to CC BY 4.0.

sion to active sensing regions resulting in decreased sensitivity. Figure 11a and Figure 11b show, respectively, a SEM image and the scaling factor with fractal dimension $D=1.75$ of the $\mathrm{TiO}_{2}$ fractals.

Sabri et al. synthesized a $\mathrm{TiO}_{2}$ structure referred to as sootderived $\mathrm{TiO}_{2}$ layers (ST) [73]. These were formed on a Pt electrode resulting in a sensor prototype and were later used for UV-assisted acetone sensing. Figure $12 \mathrm{a}$ and Figure $12 \mathrm{~b}$ show
SEM images of top-view morphology and thickness of the sample at low and high magnifications, respectively. Figure 12c shows an energy-dispersive X-ray spectroscopy (EDS) mapping of the sensor, while Figure 12d shows individual EDS maps of $\mathrm{Si}, \mathrm{Pt}, \mathrm{O}$, and Ti. The fabricated sensor displayed good sensitivity towards acetone under exposure to UV light with a detection limit greater than $97 \%$ at 10 ppb. The exceptional sensitivity achieved was attributed to high porosity, network structure, and large surface area of fractal structure. Figure $12 \mathrm{e}-\mathrm{j}$
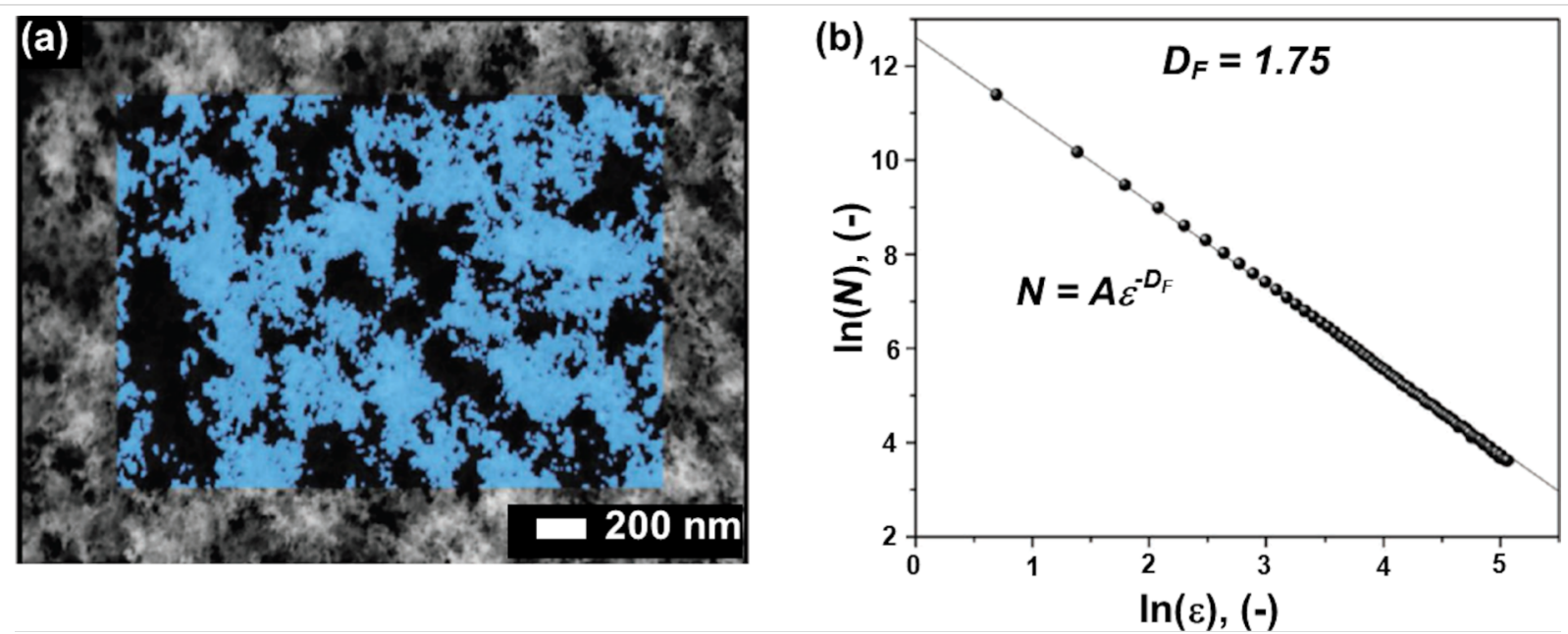

Figure 11: $\mathrm{TiO}_{2}$ fractals. (a) Top-view SEM image of $\mathrm{TiO}_{2}$ fractals. (b) Double-log plot of foreground pixel number with the scaling factor. The estimated fractal dimension was 1.75. Figure 11a,b was reproduced from [49], Z. Fusco, M. Rahmani, R. Bo, R. Verre, N. Motta, D. Neshev, A. Tricoli, "Nanostructured Dielectric Fractals on Resonant Plasmonic Metasurfaces for Selective and Sensitive Optical Sensing of Volatile Compounds", Advanced Materials, with permission from John Wiley \& Sons. Copyright $@ 2018$ WILEY-VCH Verlag GmbH \& Co. KGaA, Weinheim. This content is not subject to CC BY 4.0. 

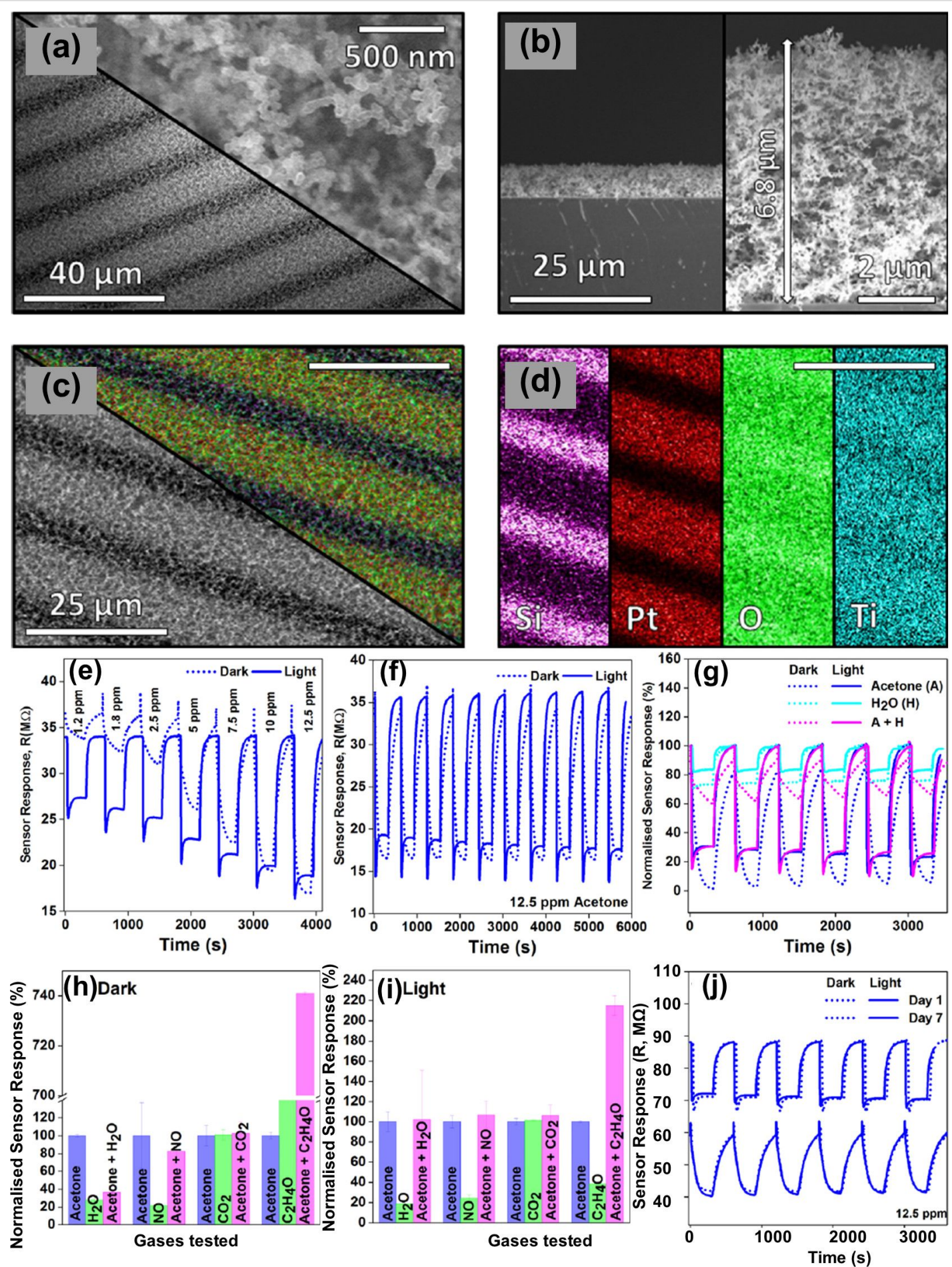

Figure 12: $\mathrm{TiO}_{2}$ fractals on candle soot templates. SEM images of (a) top-view morphology and (b) thickness of the specimen. (c) EDS maps of the deposited ST material on the sensor. (d) EDS maps for single elements $\mathrm{Si}, \mathrm{Pt}, \mathrm{O}$ and $\mathrm{Ti}$ of soot derived $\mathrm{TiO}_{2}$ layers on $\mathrm{Pt}$ electrode-based sensor, (e-j) Optical and photo-response results of ultra-porous $\mathrm{TiO}_{2}$ films. Figure 12a-j were reprinted from [73], Sensors and Actuators $\mathrm{B}$ : Chemical, vol. 275, by Y.M. Sabri; A.E. Kandjani; S.S.A.A.H. Rashid; C.J. Harrison; S.J. Ippolito; S.K. Bhargava, "Soot template $\mathrm{TiO}_{2}$ fractals as a photoactive gas sensor for acetone detection", pages no. 215-222, Copyright (2018), with permission from Elsevier. This content is not subject to CC BY 4.0.

shows the optical and photo response of ultra-porous $\mathrm{TiO}_{2}$.

These structures were estimated to have a fractal dimension of 1.77 .
Iron oxide-based fractals

Bailly et al. fabricated dendrites, cubes, rhombohedra, and spindle-shaped hematite $\alpha-\mathrm{Fe}_{2} \mathrm{O}_{3}$ fractal crystals by a cost- 
effective and eco-friendly microwave method [74]. Figure 13 shows SEM images of different hematite crystals obtained by varying precursor concentrations and additives. A dendritic particle structure with a middle stem of $3.5 \mu \mathrm{m}$ and secondary branches of ca. $1 \mu \mathrm{m}$ to $250 \mathrm{~nm}$, a structure of $700 \mathrm{~nm}$ long spindle particles, a rhombohedral structure of $80 \mathrm{~nm}$, and a cubic particle structure of $100 \mathrm{~nm}$ were obtained. The estimated fractal dimensions for dendrites, cubes, rhombohedra, and spindles were 1.56, 1.89, 1.49 and 1.81, respectively. The sensing material was deposited on an antenna, and a microwave transduction principle was employed for gas sensing. In these measurements, the interaction of the gas analyte with the sensor was studied at different frequencies and changes in the reflection coefficient and dielectric properties of sensing material were observed. The response of sensor was described by the real and imaginary parts of the reflection coefficient using a specific waveguide. The response was found to be linear for ammonia in the range of $0-500 \mathrm{ppm}$.

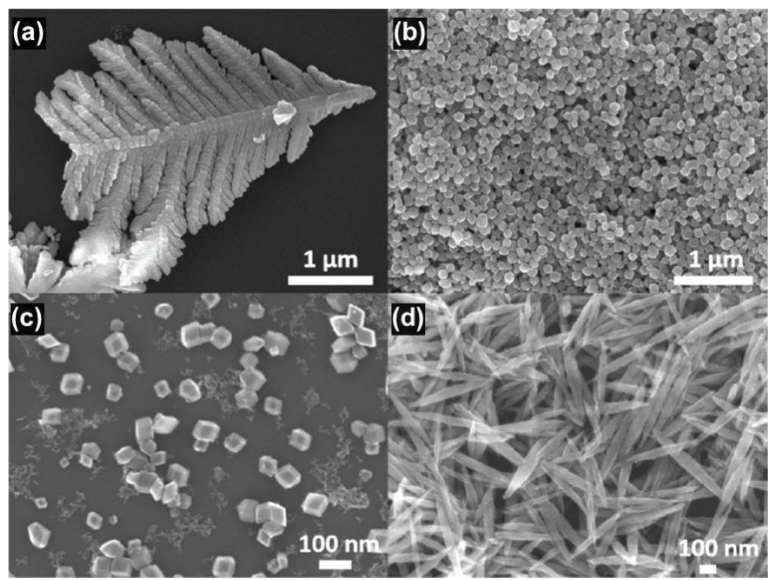

Figure 13: Hematite fractals. SEM images of (a) dendrites, (b) nanocubes, (c) rhombohedra, and (d) spindles of $\alpha-\mathrm{Fe}_{2} \mathrm{O}_{3}$. Figure 13a-d was reprinted from [74], Procedia Engineering, vol. 120, by G. Bailly; J. Rossignol; B. de Fonseca; P. Pribetich; D. Stuerga, "Shape-controlled synthesis of hematite for microwave gas sensing", pages no. 764-768, Copyright (2015), with permission from Elsevier. This content is not subject to CC BY 4.0 .

\section{Zinc oxide-based fractals}

Hierarchical dandelion-like hollow $\mathrm{ZnO}$ structures were reported by Fan et al. who annealed a zinc precursor [75] Figure 14a-f shows SEM images of $\mathrm{ZnO}$ structures obtained at different temperatures. The fabricated structures had large surface area and affluent pores and were tested for sensing ethanol vapors. The authors reported good sensing response (34.5), rapid response (6s), fast recovery time ( $7 \mathrm{~s})$, and superior selectivity towards ethanol vapors at an optimum temperature of $250{ }^{\circ} \mathrm{C}$. Figure $14 \mathrm{~g}$, h show the response curve, characteristic response, and recovery time for sensing $50 \mathrm{ppm}$ of ethanol while operating at $250{ }^{\circ} \mathrm{C}$. The porous dandelion-like structure enabled gas molecules to move through the abundant multiscale interconnected canals of the sensing material. Also, the large surface area of the dandelion-like structure enhanced the physical or chemical interactions due to availability of active adsorption sites at the surface of the sensing material. These structures were estimated to have $D$ values in the range of 1.19-1.61. In a similar study, Liu et al. reported on flower-like $\mathrm{ZnO}$ hierarchical superstructures synthesized using urea through a low-temperature hydrothermal technique [76]. The obtained 3D flower-like $\mathrm{ZnO}$ structures had highly dendritic structures with numerous nanoscale needles. Figure 15a-d depicts SEM
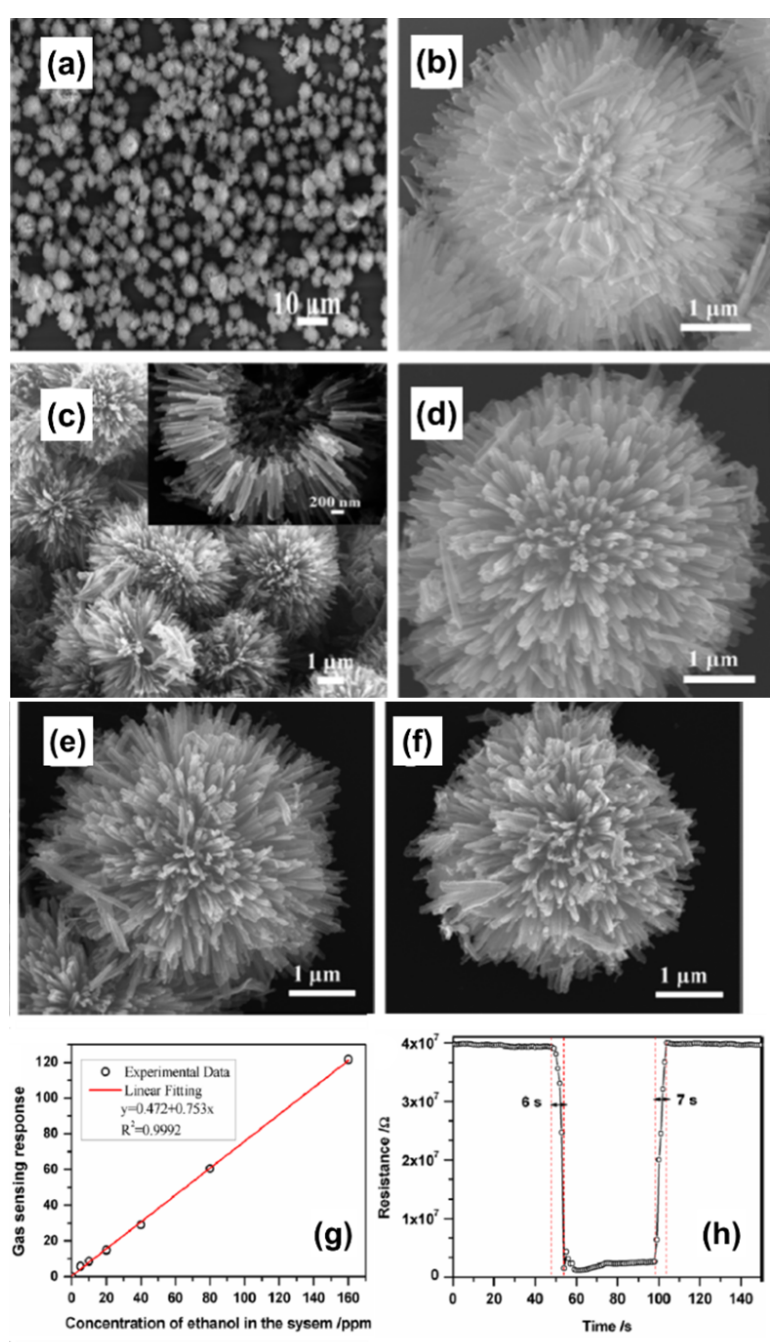

Figure 14: Dandelion-like ZnO fractals. (a-f) SEM images of the samples annealed at different temperatures. The inset in (c) shows the hollow structure of $\mathrm{ZnO}-350$, that is, the sample annealed at $350{ }^{\circ} \mathrm{C}$. (g) Response and corresponding linear fit for $\mathrm{ZnO}-350$ to different concentrations of ethanol at $250{ }^{\circ} \mathrm{C}$. (h) Response to $50 \mathrm{ppm}$ ethanol and recovery time of $\mathrm{ZnO}-350$ at an operating temperature of $250^{\circ} \mathrm{C}$.

Figure 14a-h were reproduced with permission from [75], Copyright 2014 American Chemical Society. This content is not subject to CC BY 4.0 . 
images of sample obtained after different reaction times and after using different concentration ratios of the precursors. Figure $15 \mathrm{e}-\mathrm{h}$ illustrates sensitivity and response-recovery curves for ethanol and methanol. The 3D structures provided a large surface area while the branching of the structures helped in diffusion and transport of gas molecules within the sensing material. The samples had fractal dimensions of 1.59 (after two hours of reaction) and 1.38 (after six hours of reaction).
Zang et al. demonstrated the mass production of $\mathrm{ZnO}$ dendrites and single-crystal $\mathrm{ZnO}$ dendrites up to the macroscale [77]. These were synthesized via a vapor-phase transport method at $930{ }^{\circ} \mathrm{C}$ using a copper catalyst. Figure $16 \mathrm{a}$ and Figure $16 \mathrm{~b}$ show, respectively, a schematic and a SEM image of the $\mathrm{ZnO}$ dendrite gas sensor device. The $\mathrm{ZnO}$ dendrites were composed of many well aligned nanorods. The variations in potential barrier height at the contacts of the nanorods gave excellent gas
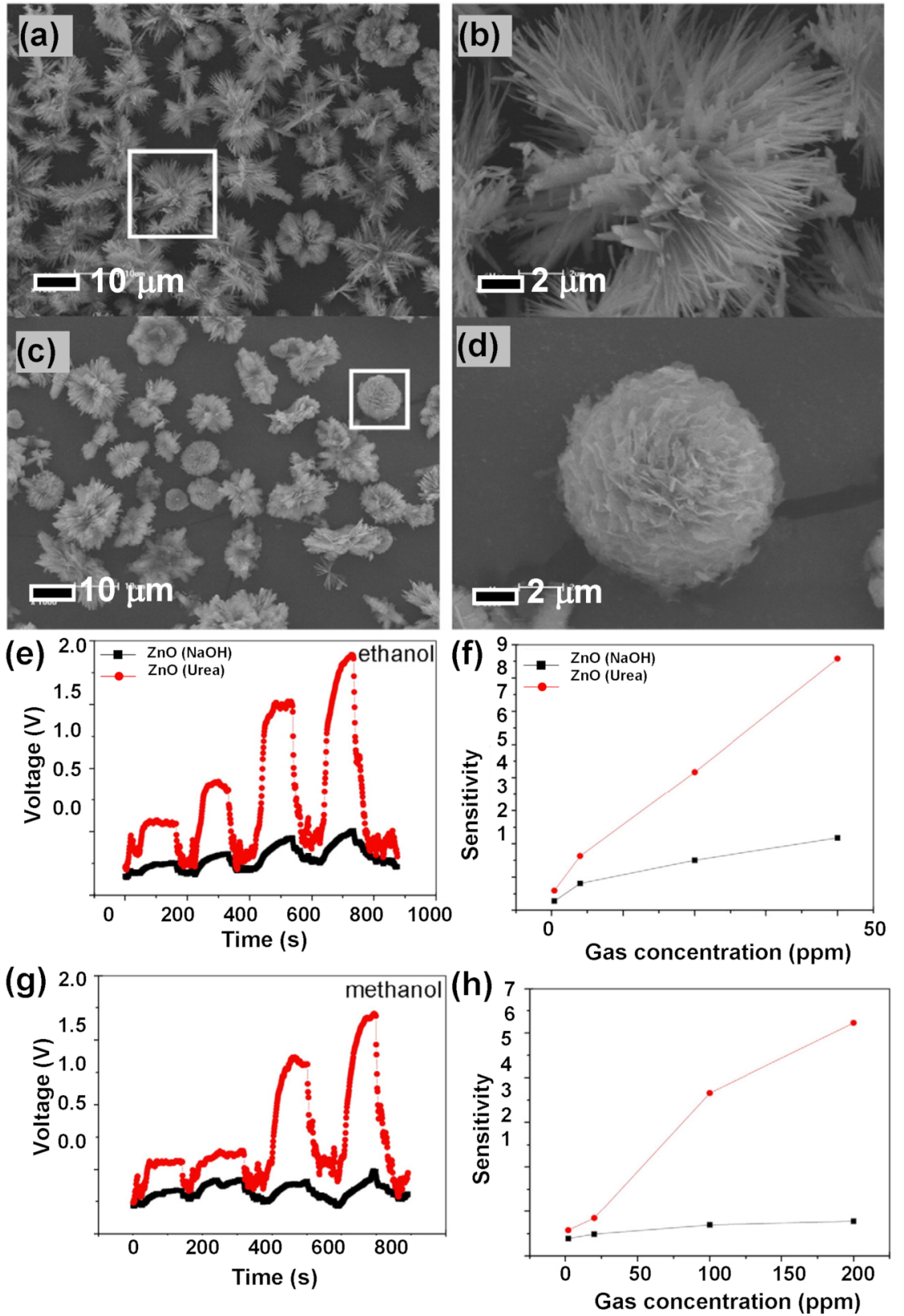

Figure 15: ZnO nanoscale flowers. SEM images of the samples prepared with a reaction time of $(\mathrm{a}, \mathrm{b}) 2 \mathrm{~h}$ and $(\mathrm{c}, \mathrm{d}) 6 \mathrm{~h}$ with a molar ratio of urea/ $/ \mathrm{Zn}^{2+}=2: 1 ;(\mathrm{e}, \mathrm{f})$ dynamic response-recovery curve and sensor sensitivity toward ethanol and $(\mathrm{g}, \mathrm{h})$ dynamic response-recovery curve and sensor sensitivity toward methanol. Figure 15a-h was reprinted from [76], Powder Technology, vol. 217, by X. Liu; J. Zhang; T. Yang; L. Wang; Y. Kang; S. Wang; S. Wu, "Self-assembled hierarchical flowerlike ZnO architectures and their gas-sensing properties", pages no. 238-244, Copyright (2012), with permission from Elsevier. This content is not subject to CC BY 4.0. 
sensing results towards hydrogen sulfide $\left(\mathrm{H}_{2} \mathrm{~S}\right)$. The sensitivity response of the $\mathrm{ZnO}$ dendrite sensor at room temperature and the variation in sensitivity at different $\mathrm{H}_{2} \mathrm{~S}$ concentrations (10-500 ppm) was studied. For $10 \mathrm{ppm}$ the sensitivity of the sensor was observed to be 3.3 while that for 500 ppm was 26.4 . The response time for the dendritic sensors was observed to be in the range of 15-20 s, and the sensors recovered in 30-50 s. These structures show a fractal dimension of 1.79 .
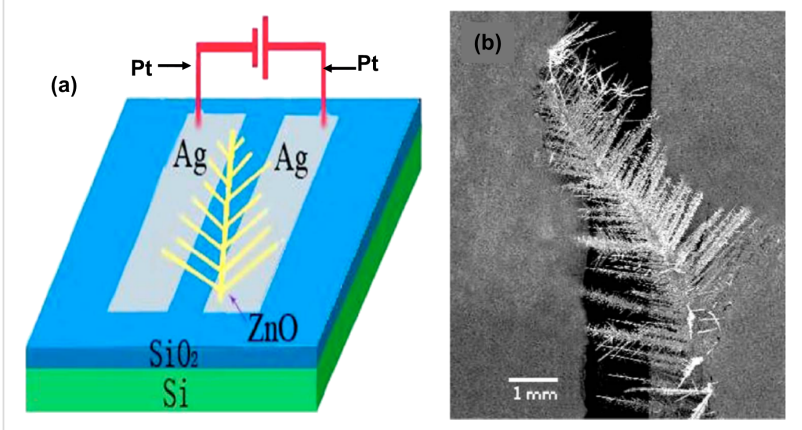

Figure 16: $\mathrm{ZnO}$ dendritic sensor. (a) Schematic illustration and (b) SEM micrograph of a $\mathrm{ZnO}$ dendrite gas sensor. Figure $16 \mathrm{a}, \mathrm{b}$ was reprinted from [77], with the permission of AIP Publishing. This content is not subject to CC BY 4.0.

\section{Tungsten oxide-based fractals}

A very recent study on the sensing of $\mathrm{NO}_{2}$, acetone, and carbon monoxide was reported by Simon and co-workers. They used $\mathrm{Ni}$ nanoparticles to decorate a reduced graphene oxide $/ \mathrm{WO}_{3}$ nanocomposite [78]. The $\mathrm{WO}_{3}$ sample annealed at $600{ }^{\circ} \mathrm{C}$ shows the presence of fractal structures. Though the authors of the work did not consider the formation of fractals in their work, the SEM image of the sample annealed at $600{ }^{\circ} \mathrm{C}$ was used to estimate the fractal dimension. The analysis shows that this particular sample had a fractal dimension of $D=1.86$. Metal-assisted chemical etching was used by Qin et al. [79] to prepare a dendritic array of $\mathrm{Si} / \mathrm{WO}_{3} \mathrm{NW}$ composites, which was tested for the detection of $\mathrm{NO}_{2}$ gas at room temperature. Figure 17a-e SEM and high-resolution transmission electron microscopy (HR-TEM) images of $\mathrm{Si} / \mathrm{WO}_{3} \mathrm{NWs}$. Figure $17 \mathrm{f}$ shows the XRD diffractograms of $\mathrm{Si} \mathrm{NWs}$ and $\mathrm{Si} / \mathrm{WO}_{3} \mathrm{NWs}$. Figure $17 \mathrm{~g}-\mathrm{j}$ demonstrates the dynamic response of composite and pure $\mathrm{Si} \mathrm{NWs}$ to $\mathrm{NO}_{2}$ at different concentrations at room temperature, and the response of the composite to different gases. The composite sensor with $\mathrm{p}-\mathrm{n}$ heterojunctions successfully transferred charge carriers and additionally served as the conduction path for electron transportation, which led to an improvement in gas sensing behavior of the composite sensor. The technique yielded structures with a fractal dimension of 1.73. In another study, $\mathrm{NO}_{2}$ sensing by $\mathrm{WO}_{3}$ dendritic nanosheets, prepared by Xiao et al. using a solvothermal method, was reported [80]. Here, the authors discussed a five-stage growth process comprising polymerization, nucleation, primary growth, secondary growth, and final growth from single nanosheets to final dendritic structures. Figure 18a and Figure 18b show SEM images of hierarchical $\mathrm{WO}_{3}$ dendrites at different magnifications. The nanostructured dendrites exhibited a higher sensitivity with a detection limit of 200 ppb towards $\mathrm{NO}_{2}$, with rapid response (7 s) and recovery time (12 s) at $5 \mathrm{ppm} \mathrm{NO}_{2}$ at an operating temperature of $140{ }^{\circ} \mathrm{C}$. Figure $18 \mathrm{c}$ shows the response curves (at $140{ }^{\circ} \mathrm{C}$ ) of the $\mathrm{WO}_{3}$ sensor to $\mathrm{NO}_{2}$. Figure $18 \mathrm{~d}$ shows the resistance as function of the time, Figure 18e shows the response and recovery times as functions of the $\mathrm{NO}_{2}$ concentration, and Figure $18 \mathrm{f}$ demonstrates the stability of the response towards $500 \mathrm{ppb}$ of $\mathrm{NO}_{2}$ for up to 15 days. The authors observed that ethanol and citric acid played a vital role in the growth of the dendrite nanostructure, which exhibited a fractal dimension of 1.94 .

\section{Bismuth vanadate -based fractals}

Zhao et al. synthesized large-scale highly uniform hyperbranched monoclinic $\mathrm{BiVO}_{4}\left(\mathrm{~h}-\mathrm{BiVO}_{4}\right)$ structures by a surfactant-free hydrothermal method [81]. The as-prepared h-BiVO structure exhibited high sensitivity towards formaldehyde and ethanol. The formation of hyperbranched structures was found to be a function of different $\mathrm{pH}$ values, proton intercalation, and dissolution processes. The sensitivity in case of $\mathrm{h}-\mathrm{BiVO}_{4}$ was found to be excellent as compared to monoclinic bismuth vanadate $\left(\mathrm{m}-\mathrm{BiVO}_{4}\right)$ at room temperature owing to the hyperbranched structure and high surface area. Figure 19a-c shows field-emission SEM (FESEM) images of hyperbranched $\mathrm{m}-\mathrm{BiVO}_{4}$, a single hyperbranch of $\mathrm{h}-\mathrm{BiVO}_{4}$, and a trunk of

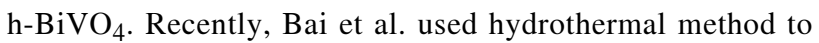
synthesize reduced graphene oxide and pine dendritic $\mathrm{BiVO}_{4}$ composite with an average length of $1-1.5 \mu \mathrm{m}$ and about $0.6 \mu \mathrm{m}$ width [82]. In the hybrid composite rGO nanosheets were draped with a pine dendritic morphology. Figure 20 shows the SEM images of GO (Figure 20a), rGO (Figure 20b), pure pine dendritic $\mathrm{BiVO}_{4}$ (Figure 20c), and the $\mathrm{BiVO}_{4} / \mathrm{rGO}$ hybrid structure (Figure 20d). The hybrid material was used for the detection of triethylamine (TEA) gas. A detection of $10 \mathrm{ppm}$ TEA with the highest response (5.91) was achieved with the hybrid composition of $\mathrm{BiVO}_{4}$ and $\mathrm{rGO}$ at $180{ }^{\circ} \mathrm{C}$ working temperature, in comparison to pure $\mathrm{BiVO}_{4}$ (1.2) and other compositions of $\mathrm{BiVO}_{4}$ and $\mathrm{rGO}$ at different temperatures $\left(80-200{ }^{\circ} \mathrm{C}\right)$. The outstanding enhancement in the response of the hybrid material with quick response and recovery times was attributed to the formation of $\mathrm{p}-\mathrm{n}$ heterojunctions between $\mathrm{rGO}$ nanosheets and dendritic $\mathrm{BiVO}_{4}$, the increased surface area of dendritic structures, as well as conductivity and acceleration of electrons between gas molecules and hybrid material. Figure 20e shows responses of pure $\mathrm{BiVO}_{4}$ and $\mathrm{BiVO}_{4} / \mathrm{rGO}$ hybrids towards 10 ppm TEA with different rGO mass ratios at differ- 

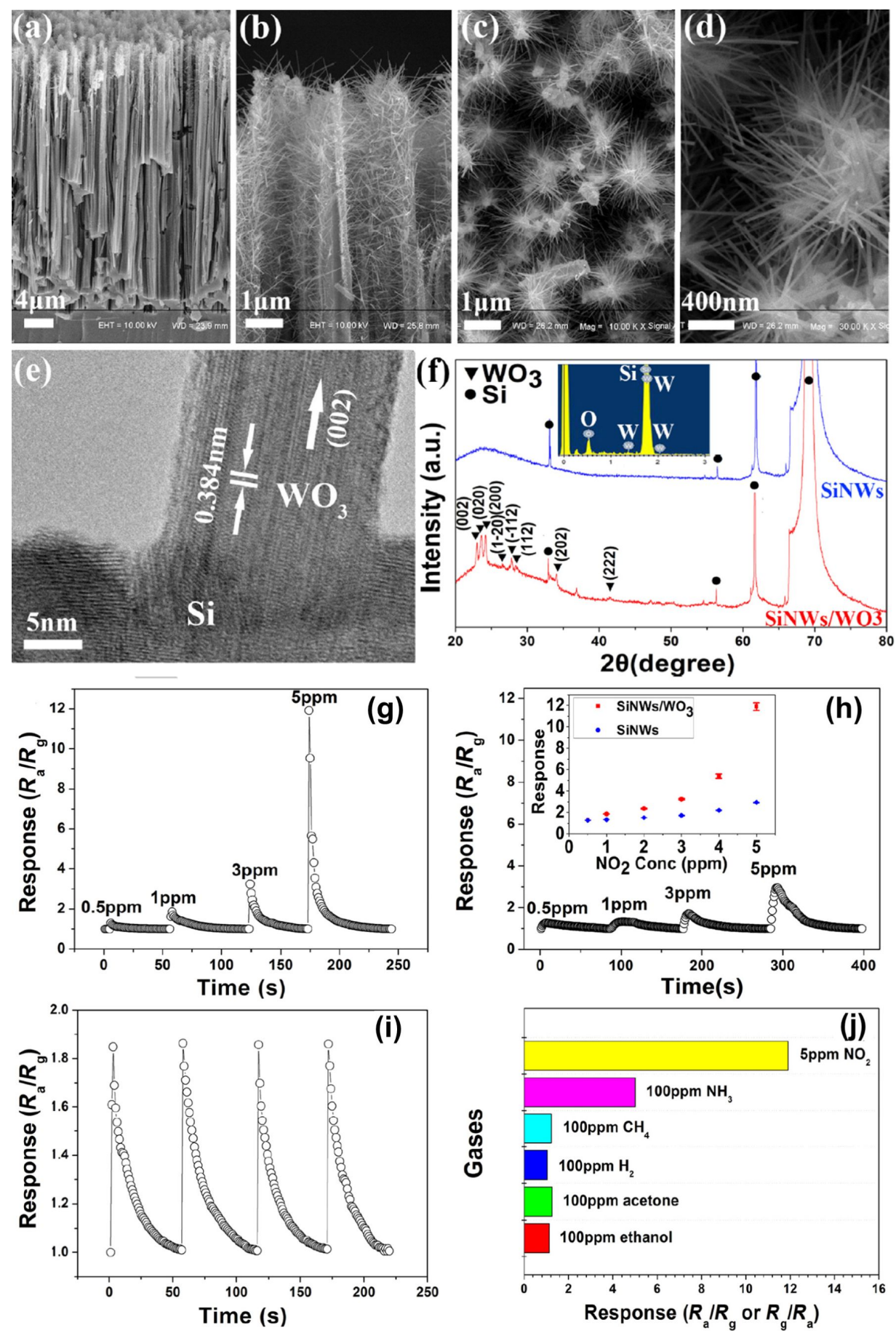

Figure 17: $\mathrm{Si} / \mathrm{WO}_{3}$ nanowires. (a-d) SEM images of $\mathrm{Si} / \mathrm{WO}_{3} \mathrm{NWs}$, (e) HRTEM image of a $\mathrm{WO}_{3} / \mathrm{SiNW}$ interface, (f) XRD pattern of SiNWs and $\mathrm{SiNWs} / \mathrm{WO}_{3}$. Dynamic responses of $(\mathrm{g})$ the composite and $(\mathrm{h})$ pure SiNWs to $0.5-5 \mathrm{ppm} \mathrm{NO} \mathrm{N}_{2}$ at room temperature; (i) four cycles of dynamic response of the composite sensor to $1 \mathrm{ppm} \mathrm{NO}_{2}$; (j) response of the composite sensor to different gases. The inset in (h) shows the response values at different $\mathrm{NO}_{2}$ concentrations. Figure 17a-j was reprinted from [79], Materials Letters, vol. 207, by Y. Qin; Z. Wang; D. Liu; K. Wang, "Dendritic composite array of silicon nanowires $/ \mathrm{WO}_{3}$ nanowires for sensitive detection of $\mathrm{NO}_{2}$ at room temperature", pages no. 29-32, Copyright (2017) with permission from Elsevier. This content is not subject to CC BY 4.0.

ent temperatures. Figure 20f and Figure 20g show, respectively, resistance and response curves for the sensor based on the $\mathrm{BiVO}_{4} / 13.0$ wt $\%$ rGO hybrid material to different concentra- tions of TEA at $180{ }^{\circ} \mathrm{C}$. Figure $20 \mathrm{~h}$ illustrates responses of sensors based on pure $\mathrm{BiVO}_{4}$ and the $\mathrm{BiVO}_{4} / \mathrm{rGO}$ hybrid material towards $10 \mathrm{ppm}$ TEA at $35 \% \mathrm{RH}$. 

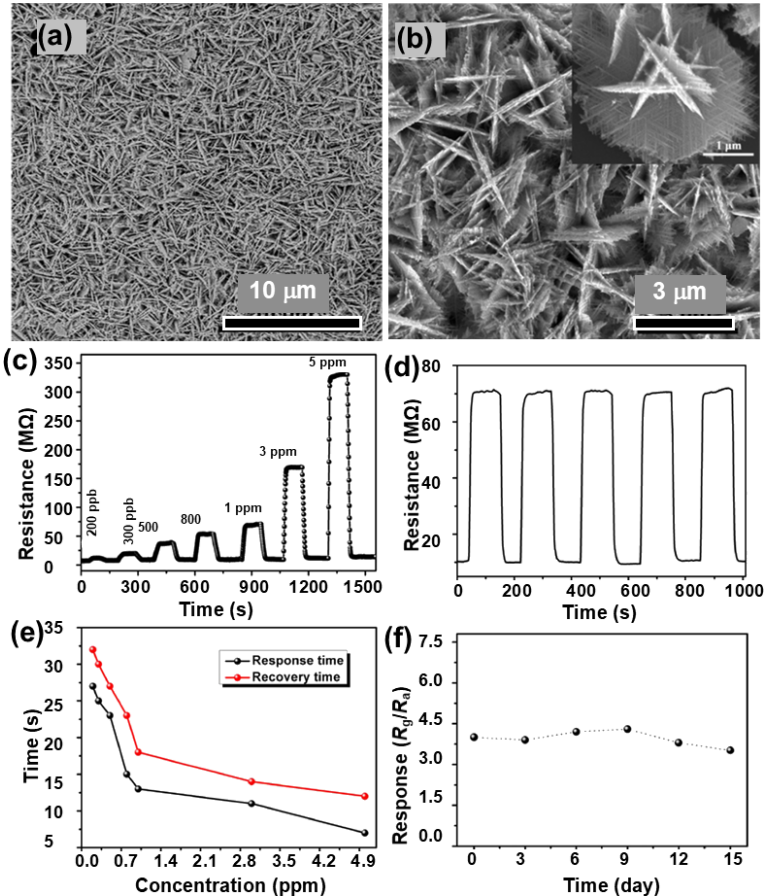

Figure 18: $\mathrm{WO}_{3}$ dendrites. (a, b) SEM images of the grown hierarchical $\mathrm{WO}_{3}$ dendrites at low and high magnification; (c) dynamic response curves of the $\mathrm{WO}_{3}$ sensor as function of the $\mathrm{NO}_{2}$ concentration; (d) typical response curve cycling to $500 \mathrm{ppb}$ of $\mathrm{NO}_{2}$ at $140{ }^{\circ} \mathrm{C}$; (e) variations in response and recovery times at $140{ }^{\circ} \mathrm{C}$ as function of the $\mathrm{NO}_{2}$ concentration; (f) stability study of the sensor exposed to $500 \mathrm{ppb} \mathrm{NO}$ at $140^{\circ} \mathrm{C}$. Figure $18 \mathrm{a}-\mathrm{f}$ were reprinted from [80], Ceramics International, vol. 43, by B. Xiao; D. Wang; F. Wang; $Q$. Zhao; C. Zhai; M. Zhang, "Preparation of hierarchical $\mathrm{WO}_{3}$ dendrites and their applications in $\mathrm{NO}_{2}$ sensing", pages no. 8183-8189, Copyright (2017), with permission from Elsevier. This content is not subject to CC BY 4.0.

\section{Cadmium sulfide-based fractals}

Highly oriented CdS dendrite (HOCSD) sensors synthesized by a hydrothermal method to detect formic acid $(\mathrm{HCOOH})$ and hydrazine $\left(\mathrm{N}_{2} \mathrm{H}_{4}\right)$ were reported by Guo and co-workers [83]. The multichannel branches of dendritic structure of the CdS sensor allowed gas molecules to penetrate the sensor more easily. The response and recovery times for a small concentration of $\mathrm{HCOOH}$ (ca. $50 \mathrm{ppm}$ ) was reported to be ca. $27 \mathrm{~s}$ and $21 \mathrm{~s}$ at $260{ }^{\circ} \mathrm{C}$, respectively. Figure $21 \mathrm{a}-\mathrm{e}$ shows SEM, TEM and HR-TEM images of the CdS dendrites. The CdS dendrites were shown to have superior diffusion and adsorption/desorption properties. Also, there was a synergistic effect of hydrogen bond formation and reducing abilities of the tested gas. Figure 21f and Figure 21g illustrate response and recovery time curves of the sensor when exposed to vapors of formic and acetic acid at $260{ }^{\circ} \mathrm{C}$, respectively. Figure $21 \mathrm{~h}$ and Figure $21 \mathrm{i}$ show the response as function of the concentration of the HOCSD sensor and response transients towards $50 \mathrm{ppm}$ of $\mathrm{HCOOH}$ at $260{ }^{\circ} \mathrm{C}$, respectively. Figure $21 \mathrm{j}$ and Figure $21 \mathrm{k}$
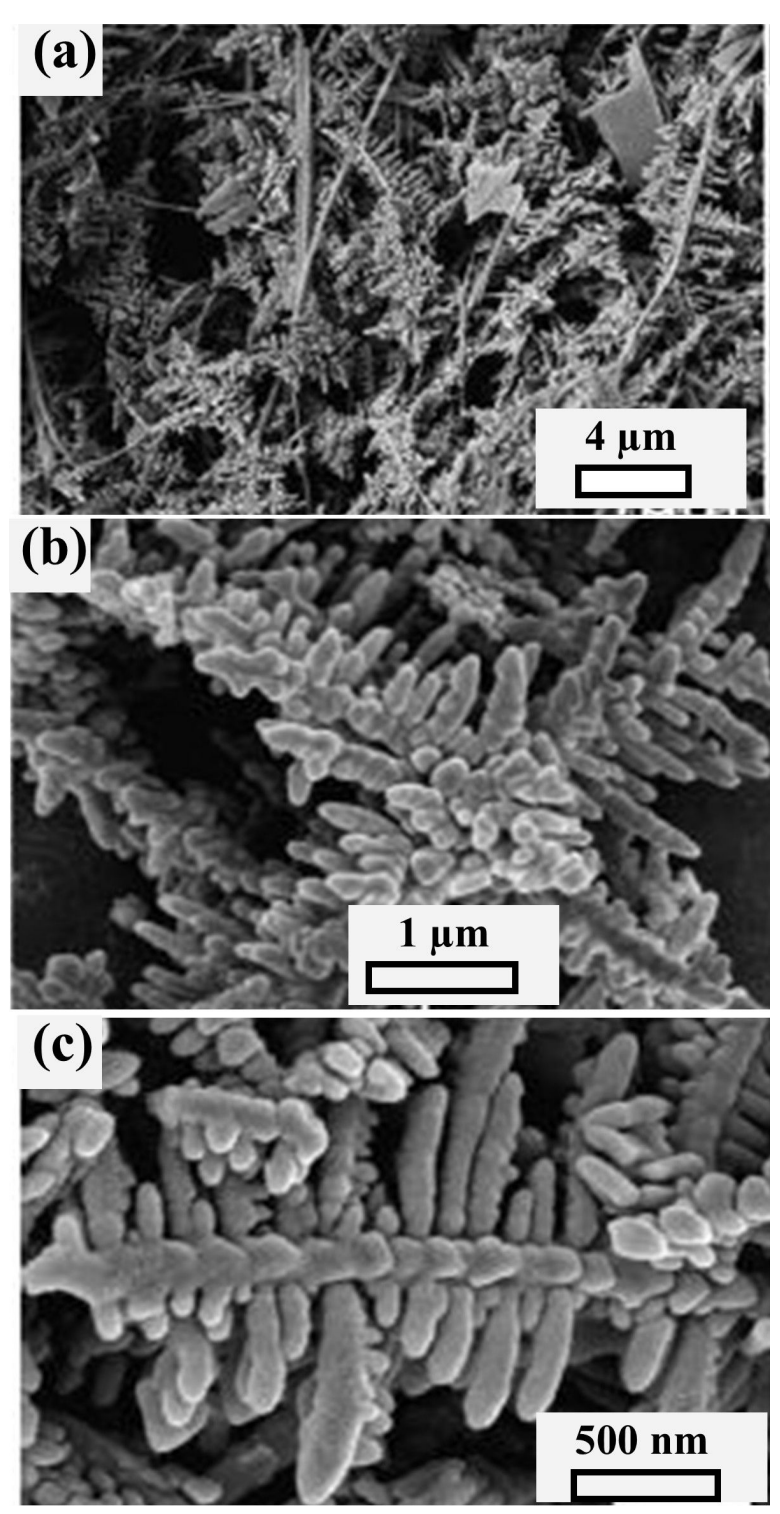

Figure 19: Bismuth vanadate hyperbranched structures. (a) FESEM

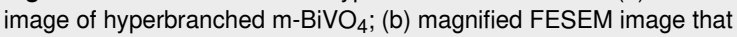
shows a single hyperbranch of $\mathrm{h}-\mathrm{BiVO}_{4}$; (c) magnified FESEM image that shows the trunk of $h-B_{i V O}$. Figure $19 a-c$ are reproduced from [81], Y. Zhao, Y. Xie, X. Zhu, S. Yan, S. Wang, "Surfactant-Free Synthesis of Hyperbranched Monoclinic Bismuth Vanadate and its Applications in Photocatalysis, Gas Sensing, and Lithium-lon Batteries", Chemistry - A European Journal, with permission from John Wiley \& Sons. Copyright @ 2008 WILEY-VCH Verlag GmbH \& Co. KGaA, Weinheim. This content is not subject to CC BY 4.0.

show the dynamic response curve for $\mathrm{N}_{2} \mathrm{H}_{4}$ and $n$ - $\mathrm{BuNH}_{2}$ with varying concentrations at an operating temperature of $260{ }^{\circ} \mathrm{C}$, while Figure 211 and Figure $21 \mathrm{~m}$ show the response towards $50 \mathrm{ppm}$ of $\mathrm{N}_{2} \mathrm{H}_{4}$ at $260{ }^{\circ} \mathrm{C}$.

\section{Other oxide-based fractals}

In 2020, Tran-Phu et al. demonstrated the formation of threedimensional fractals of $\mathrm{Au}-\mathrm{Bi}_{2} \mathrm{O}_{3}$, having $D \approx 1.80$, on a sub- 

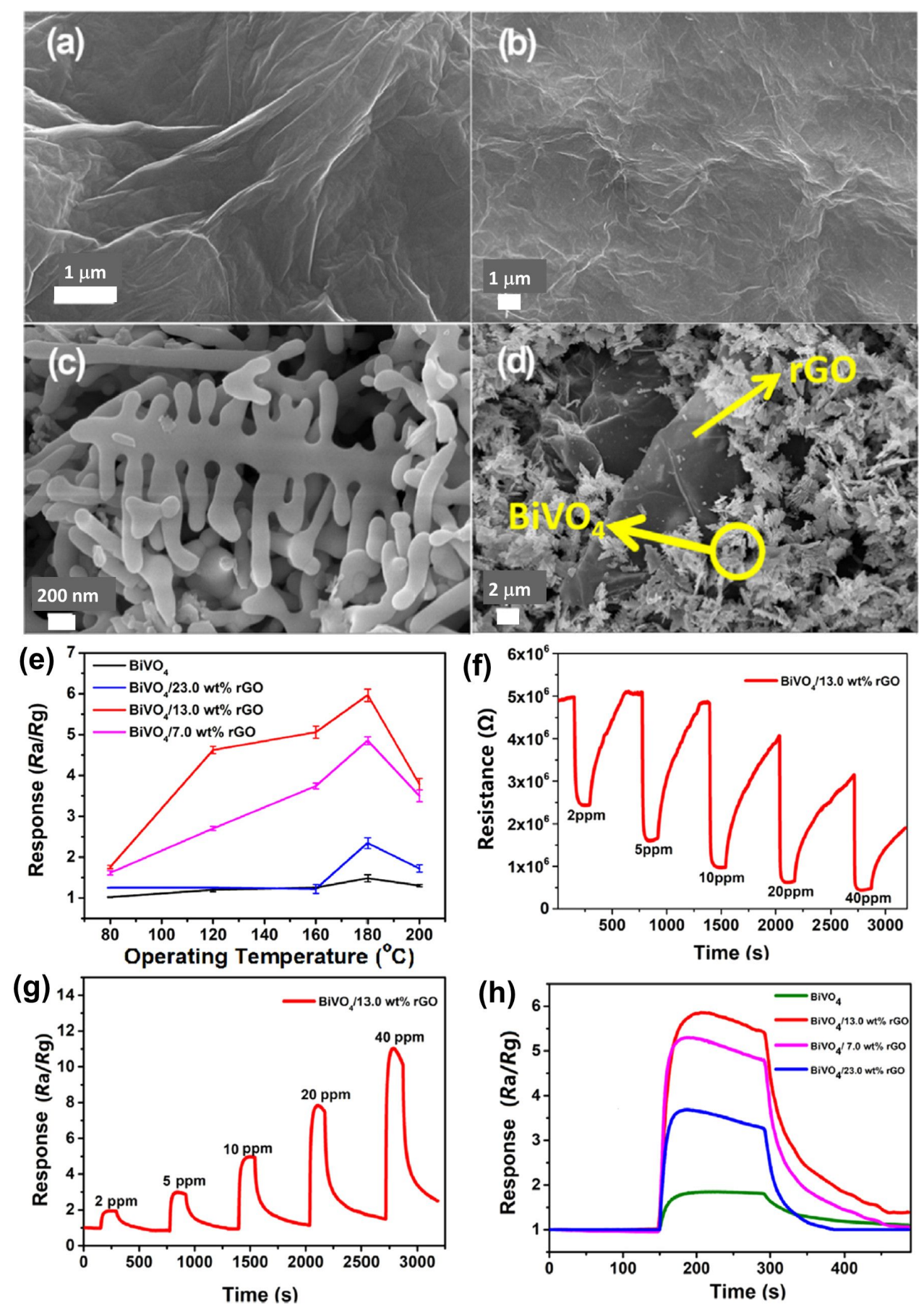

Figure 20: Bismuth vanadate dendrites. SEM images of (a) GO, (b) rGO, (c) pure pine dendritic $\mathrm{BiVO}_{4}$, and (d) $\mathrm{BiVO}_{4} / \mathrm{rGO}$ hybrid; (e) response of pure $\mathrm{BiVO}_{4}$ and $\mathrm{BiVO}_{4} / \mathrm{rGO}$ hybrids towards $10 \mathrm{ppm}$ TEA at different operating temperatures and $35 \%$ relative humidity; (f, g) resistance and response curves for a sensor based on $\mathrm{BiVO}_{4} / 13.0 \mathrm{wt} \% \mathrm{rGO}$ to different concentrations of TEA at $180{ }^{\circ} \mathrm{C}$; (h) response of pure $\mathrm{BiVO}_{4}$ and $\mathrm{BiVO}_{4} / \mathrm{rGO}$ hybrids towards $10 \mathrm{ppm}$ TEA and $35 \%$ relative humidity. Figure 20a-h was reprinted from [82], Journal of Colloid and Interface Science, vol. 587, by S. Bai; L. Sun; J. Sun; J. Han; K. Zhang; Q. Li; R. Luo; D. Li; A. Chen, "Pine dendritic bismuth vanadate loaded on reduced graphene oxide for detection of low concentration trimethylamine", pages no. 183-191, Copyright (2021), with permission from Elsevier. This content is not subject to CC BY 4.0.

strate by hot-aerosol synthesis [45]. The fabricated $\mathrm{Au}-\mathrm{Bi}_{2} \mathrm{O}_{3}$ porous fractal structures contained abundant active sites for the adsorption of carbon dioxide and other VOCs. An improve- ment of the electron density was attributed to gold nanoparticles. The resulting fractal structures showed excellent sensing properties towards VOCs (100 ppm at room temperature). The 

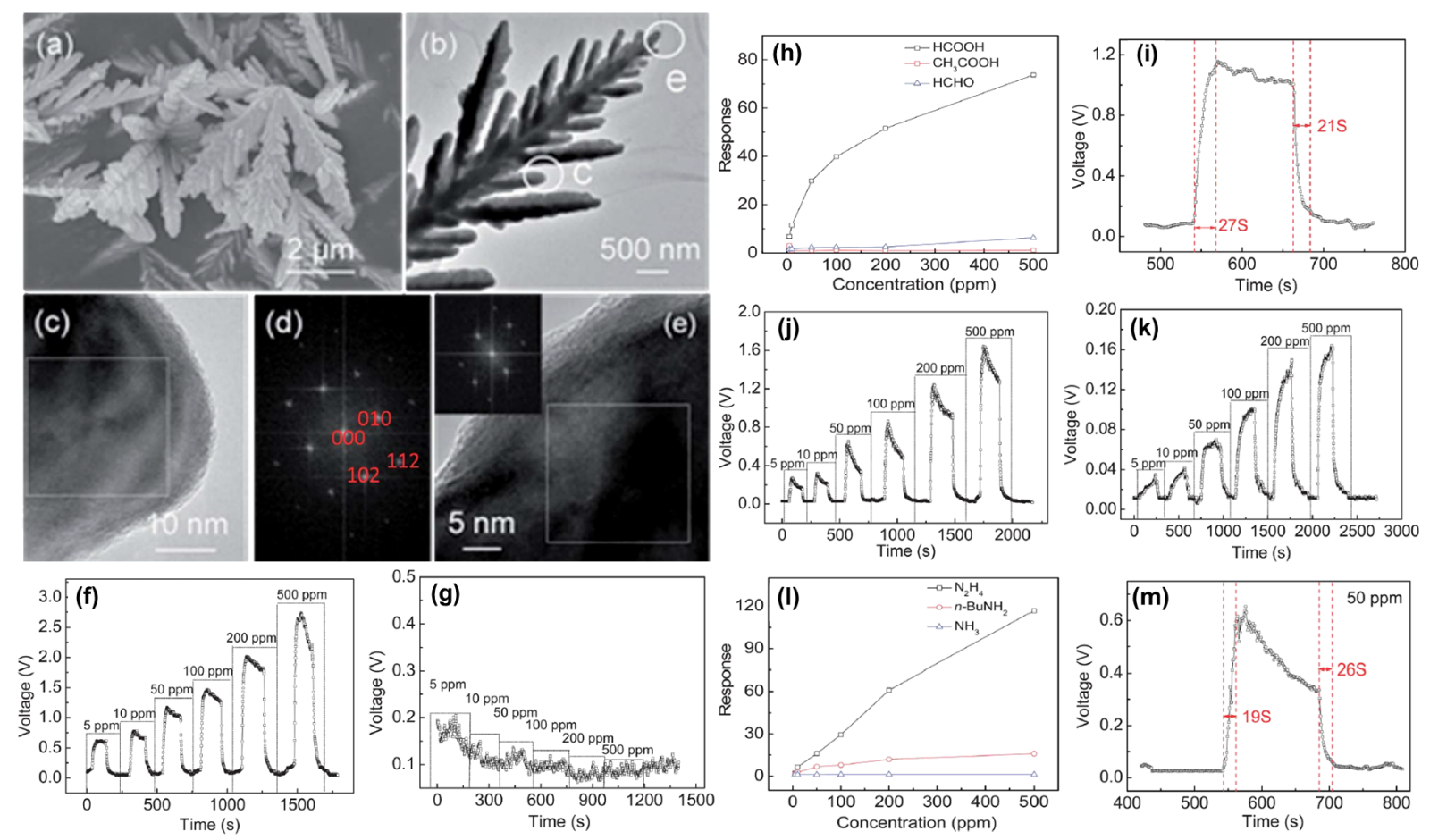

Figure 21: CdS dendrites. (a, b) CdS dendrites observed under SEM and TEM. The marked regions "c" and "e" were explored further; (c) HR-TEM and (d) FFT images of the region marked as "c"; (e) HR-TEM and (f) and FFT images of the region marked as "e". ( $f, g)$ Dynamic response-recovery curves of the sensor to formic and acetic acid vapors at different concentrations at $260{ }^{\circ} \mathrm{C}$, respectively; (h) response as function of the gas concentration of the HOCSD sensor; (i) response transients of the sensor to $50 \mathrm{ppm} \mathrm{HCOOH}$ at $260^{\circ} \mathrm{C}$; (j, k) dynamic response-recovery curves of the sensor to $\mathrm{N}_{2} \mathrm{H}_{4}$ and $n-\mathrm{BuNH}_{2}$ at different concentrations at $260^{\circ} \mathrm{C}$, respectively; (I) response as function of the gas concentration of the HOCSD sensor; $(\mathrm{m})$ response transients of the sensor to $50 \mathrm{ppm} \mathrm{N}_{2} \mathrm{H}_{4}$ at $260{ }^{\circ} \mathrm{C}$. Figure $21 \mathrm{a}-\mathrm{m}$ was republished with permission of The Royal Society of Chemistry from [83] ("Synergistic effect of the reducing ability and hydrogen bonds of tested gases: highly orientational CdS dendrite sensors" by W. Guo et al., J. Mater. Chem. A, vol. 2, issue 4, ( 2014); permission conveyed through Copyright Clearance Center, Inc. This content is not subject to CC BY 4.0 .

samples were used in the electrochemical reduction of carbon dioxide and for an optical sensor based on LSPR. Figure 22a shows the $\mathrm{Au}-\mathrm{Bi}_{2} \mathrm{O}_{3}$ fractal structures and the optical sensing of formate and toluene. Figure $22 \mathrm{~b}$ and Figure 22c show SEM images of the sample on carbon fiber paper and a glass substrate, respectively. Figure 22d illustrates the SEM image of $\mathrm{Au}-\mathrm{Bi}_{2} \mathrm{O}_{3}$ fractal employed for box-counting. Figure $22 \mathrm{e}-\mathrm{g}$ shows the estimation of the fractal dimensions of the fabricated cluster.

Pang et al. synthesized a dendrite-like $\mathrm{Co}_{3} \mathrm{O}_{4}$ nanostructure composed of numerous nanorods $(15-20 \mathrm{~nm}$ diameter and 2-3 $\mu$ m length) by a hydrothermal method and calcined the fabricated nanostructure precursors in air [84]. Figure 23a-f shows SEM and TEM micrographs with selected-area electron diffraction (SAED) patterns of the $\mathrm{Co}_{3} \mathrm{O}_{4}$ nanostructures. Hydrogen peroxide $\left(\mathrm{H}_{2} \mathrm{O}_{2}\right)$ was detected by an electrochemical sensor based on the $\mathrm{Co}_{3} \mathrm{O}_{4}$ fractals. The results confirmed that the $\mathrm{Co}_{3} \mathrm{O}_{4}$ dendritic sensor exhibited a higher sensitivity than a commercial $\mathrm{Co}_{3} \mathrm{O}_{4}$ sensor. Figure $23 \mathrm{~g}-\mathrm{j}$ show the $\mathrm{H}_{2} \mathrm{O}_{2}$ detection results. The fractals were estimated to have a fractal dimen- sion of 1.74. Wang et al. [85] synthesized a Christmas tree-like structure of nanoscale $\mathrm{Zn}$-doped nickel oxide dendritic crystals by an electrolytic method with high-temperature oxidation for the detection of $\mathrm{NH}_{3}$ at room temperature. Zn-doped $\mathrm{NiO}$ dendritic crystals at the nanoscale consisted of a major elongated stem having numerous secondary and tertiary branches. The dendritic nanostructure allowed the network passage for electron transfer after ammonia molecules interact with the sensing surface. It showed an about 5-8 times enhanced response and an improvement in recovery time by about 30-50 times compared to a pristine NiO sensor. The sensor also showed good reproducibility, high stability, and selectivity towards ammonia over other gases.

In 2015, Zhao et al. reported dandelion-like NiO hierarchical structures assembled with dendritic elements (ca. $1.8 \mu \mathrm{m}$ ) synthesized via a surfactant-free one-step hydrothermal route [86]. The dandelion-like NiO hierarchical structures had an incredibly rough surface and many gaps among them. These structures demonstrated a good response to $100 \mathrm{ppm}$ ethanol with very quick response $(2 \mathrm{~s})$ and recovery time $(12 \mathrm{~s})$ at $240{ }^{\circ} \mathrm{C}$. 

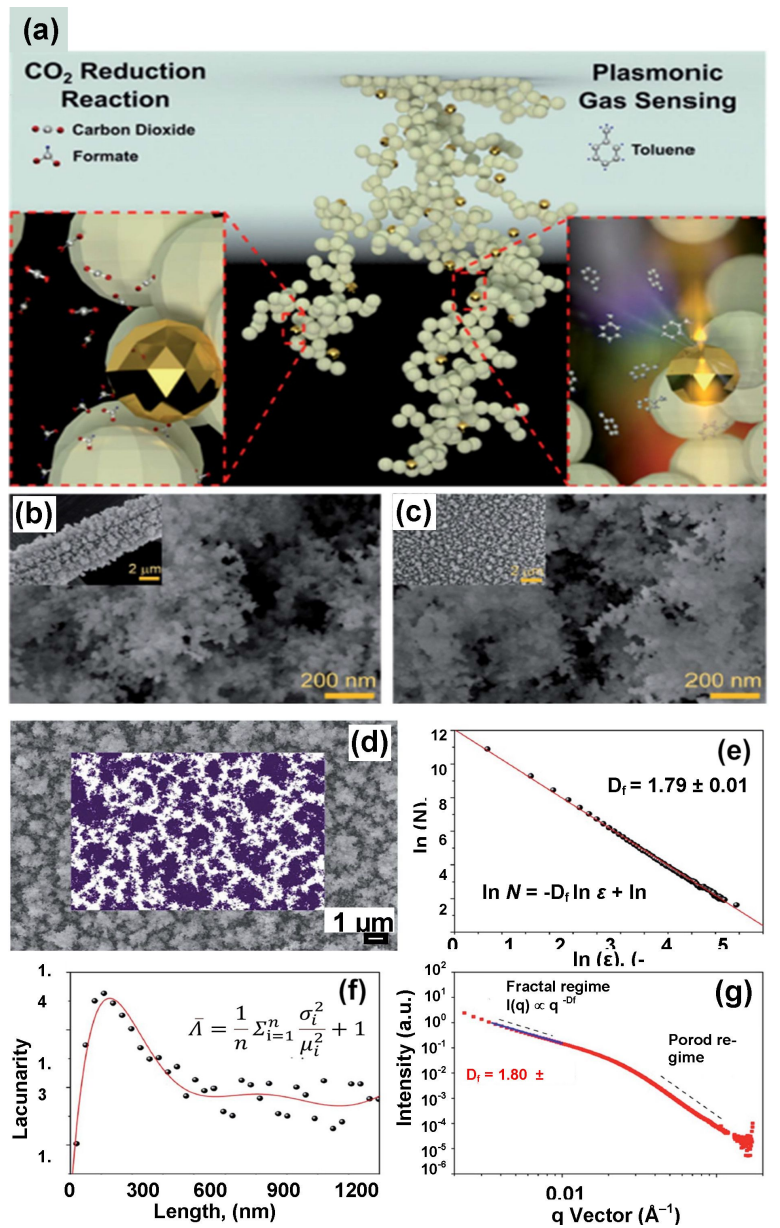

Figure 22: $\mathrm{Au}-\mathrm{Bi}_{2} \mathrm{O}_{3}$ fractals. (a) Schematic of a $\mathrm{Au}-\mathrm{Bi}_{2} \mathrm{O}_{3}$ fractal shown with magnified regions showing reduction of $\mathrm{CO}_{2}$ to formate (left) and optical gas sensing of toluene (right); (b, c) SEM images of the sample on carbon fiber paper and glass, respectively; (d) SEM image of $\mathrm{Au}-\mathrm{Bi}_{2} \mathrm{O}_{3}$ (inset: fractal analysis using the box-counting method); (e) fractal dimension of 1.79; (f) lacunarity of the $\mathrm{Au}-\mathrm{Bi}_{2} \mathrm{O}_{3}$ film. (g) Double-log plot of scattering intensity and vector $q$ measured by small angle $\mathrm{X}$-ray scattering of the $\mathrm{Au}-\mathrm{Bi}_{2} \mathrm{O}_{3}$ film on a glass substrate. Figure $22 \mathrm{a}-\mathrm{g}$ was republished with permission of The Royal Society of Chemistry from [45] ("Multifunctional nanostructures of $\mathrm{Au}-\mathrm{Bi}_{2} \mathrm{O}_{3}$ fractals for $\mathrm{CO}_{2}$ reduction and optical sensing" by $\mathrm{T}$. TranPhu et al., J. Mater. Chem. A, vol.8, issue 22, (c) 2020); permission conveyed through Copyright Clearance Center, Inc. This content is not subject to CC BY 4.0.

The better sensitivity and faster response and recovery times were due to the hierarchical structure, inherent rough surfaces, and gaps acting as diffusion channels.

\section{Gas-sensing mechanism of fractal structures}

There are a number of models to explain the function of conductometric SMO gas sensors. For instance, electron depletion layer (for n-type materials) or hole accumulation layer theory (for p-type), fermi level control theory, and grain boundary barrier control theory models have been proposed to understand the fundamentals of sensing mechanism $[31,36,87,88]$.
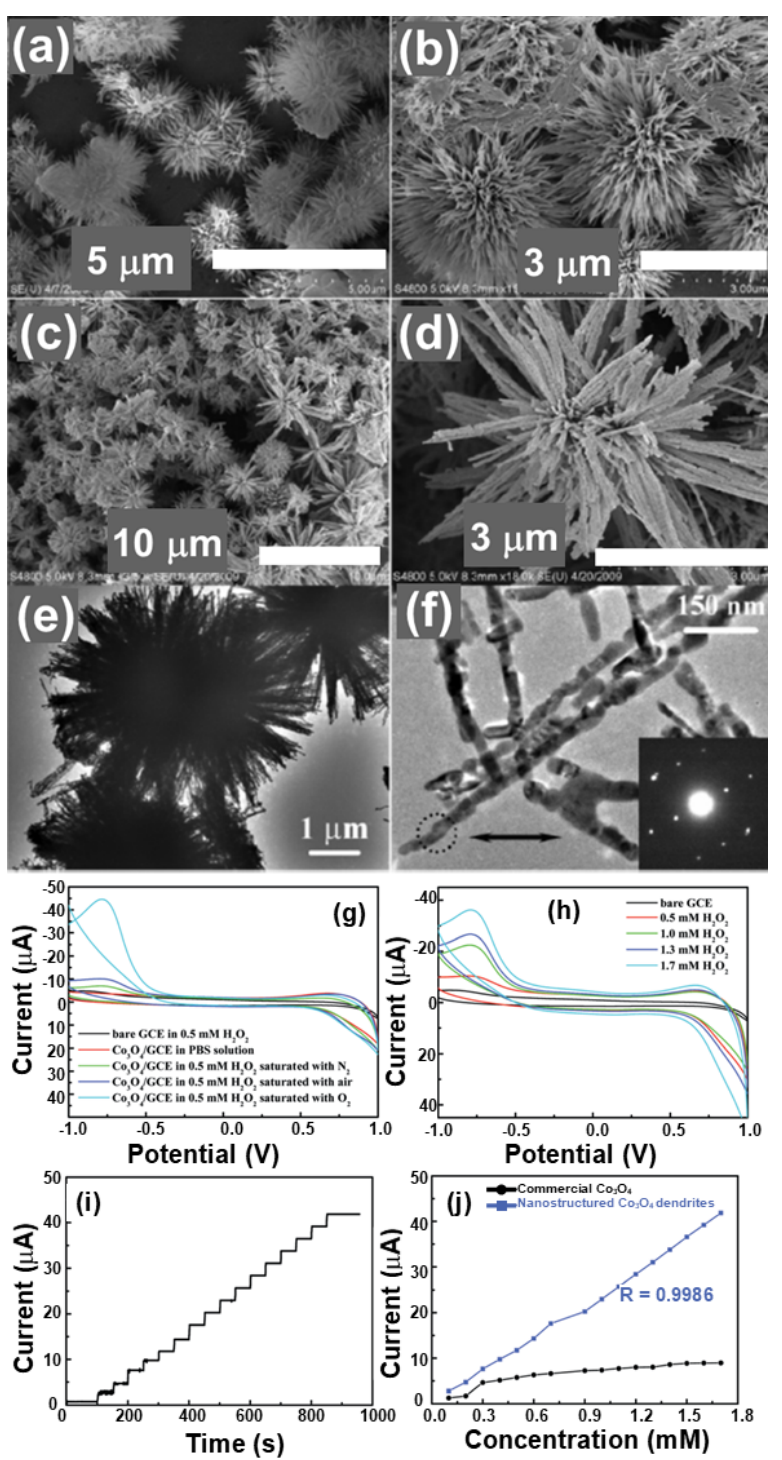

Figure 23: $\mathrm{Co}_{3} \mathrm{O}_{4}$ dendrites. SEM images of $(a, b)$ precursor and (c, d) $\mathrm{Co}_{3} \mathrm{O}_{4}$ nanostructure; (e, f) TEM images of the $\mathrm{Co}_{3} \mathrm{O}_{4}$ nanostructure (inset in (f): SAED pattern of the encircled area); (g) CV curves of a bare glassy carbon electrode (GCE) and a GCE modified with the as-prepared $\mathrm{Co}_{3} \mathrm{O}_{4}$ nanostructure recorded in $0.05 \mathrm{M} \mathrm{PBS}(\mathrm{pH} 7.40)$ solution saturated with different gases; (h) CV curves of a GCE modified with $\mathrm{Co}_{3} \mathrm{O}_{4}$ nanostructures at different concentrations of $\mathrm{H}_{2} \mathrm{O}_{2}$ saturated with $\mathrm{N}_{2}$ recorded in $0.05 \mathrm{M}$ PBS ( $\mathrm{pH} 7.40$ ); (i) amperometry response at $-0.77 \mathrm{~V}$ to successive increments of $\mathrm{H}_{2} \mathrm{O}_{2}$ concentration; (j) current as function of the $\mathrm{H}_{2} \mathrm{O}_{2}$ concentration measured with different $\mathrm{Co}_{3} \mathrm{O}_{4}$-modified GCEs. Figure $23 \mathrm{a}$-j was republished with permission of The Royal Society of Chemistry from [84] ("Dendrite-like $\mathrm{Co}_{3} \mathrm{O}_{4}$ nanostructure and its applications in sensors, supercapacitors and catalysis", H. Pang et al., Dalton Trans., vol. 41, issue19, ( 2012); permission conveyed through Copyright Clearance Center, Inc. This content is not subject to CC BY 4.0.

The changes in electrical resistance of materials from a microscopic viewpoint are addressed by electronic and chemical sensitization mechanisms [26]. The mechanisms focusing on a macroscopic perspective deal with adsorption/desorption of surface atomic/molecular species or discuss how the bulk resis- 
tance and gas diffusion control mechanisms affect the charge transport $[26,87,89]$. The changes in electrical resistance of the material upon interaction with target gas analytes arise due to changes in, for instance, energy bands, surface charge, and work function caused by temperature, grain size, crystal plane energies, and doping $[87,90,91]$. Thus, there is no single sensing mechanism that explains all SMO gas sensors. The section "Fractal length scales and growth models" described various fab-fracs tested as gas sensors for different analytes. The role of the morphology of fab-fracs in the gas sensing response will now be discussed.

Figure 24 explains the common mechanisms of physical adsorption, chemical linkages, gas diffusion, and fractal interconnectivity and channels. It is known that nanocrystalline gas sensor materials have better sensitivity because of their large surface area [92]. Fractal structures have dimensions that can range from micrometers to millimeters, but they primarily are composed of nanostructures that have aligned themselves in some specific way guided by surface diffusion during their growth. The transition of a fractal structure from one lengthscale to another is the result of self-organization and/or re-orga- nization process. Since fractals grow primarily via diffusion, the network is usually always continuous thereby serving as an underlying porous network decorated with three-dimensional unique geometric structures. The fab-frac structures comprise building blocks at different length scales of varying sizes and orientations. The abundant accessibility of intercrossing and interconnections of these building blocks with each other result in the formation of 3D porous network structures. This increases coarsening, roughness, and adsorption sites and overall offers a high surface-to-volume ratio [72,82,91]. The crossovers offer additional secondary and tertiary adsorption sites. Thus, the extension of fractals in all three dimensions not only adds to the total number of active adsorption sites but also enhances their density. It is well known that surface gas adsorption and desorption are the rate-determining steps and mostly depend on surface characteristics such as surface area, roughness, porosity, branching, network structure, and fractal dimensions. The fractal dimensions estimated in the present article show that structures with $D$ in the range of 1.3-1.8 exhibit better gas sensing responses. For fractal dimensions greater than 2 , gas sensing behavior is not significant, and this could be due to grain boundary resistance, which controls the charge transport

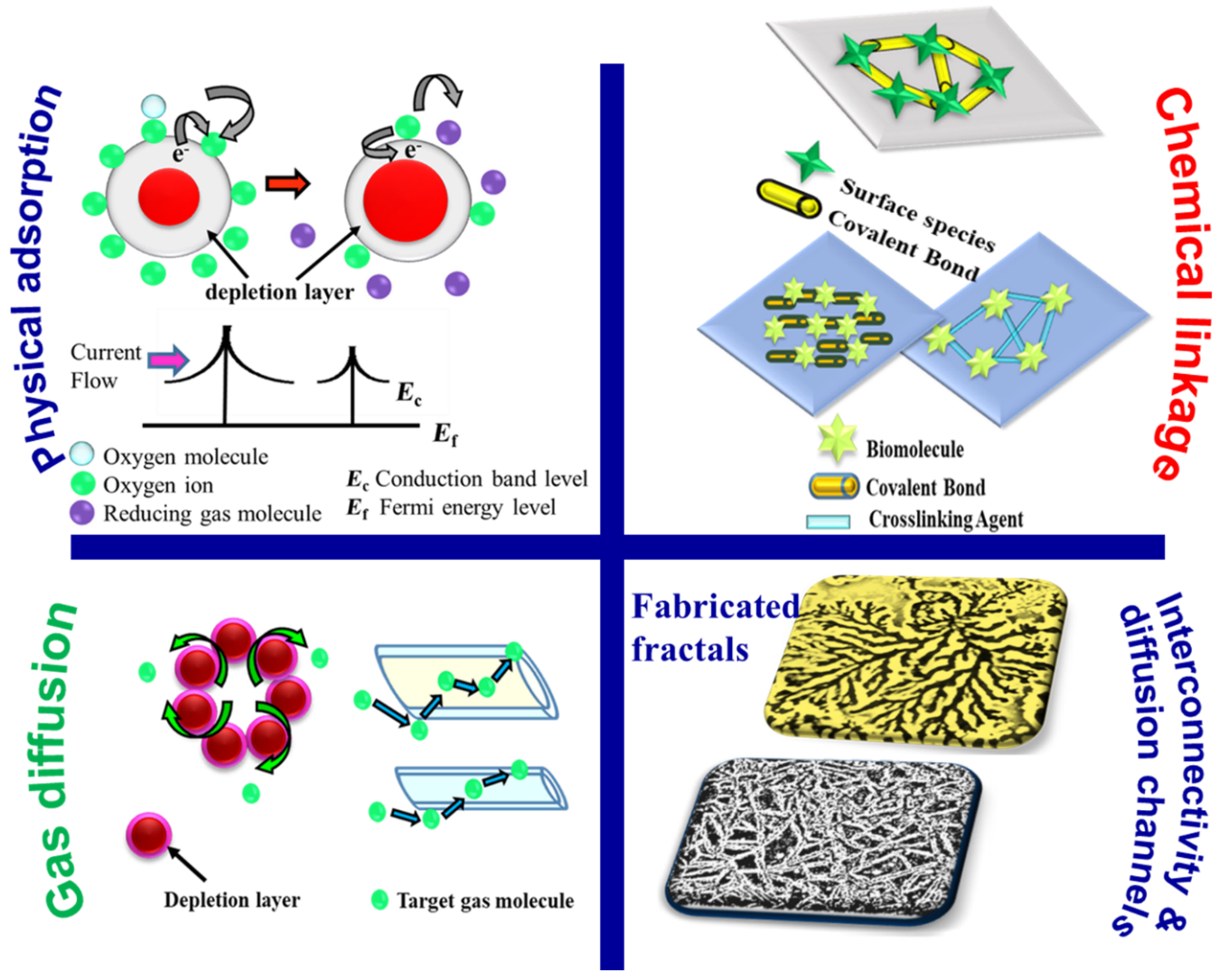

Figure 24: Gas sensing mechanisms. The schematic presents the different mechanisms through which SMO sensors can interact with analyte gases. The pore network, channel interconnectivity, and crossover points in case of fab-fracs are also shown. 
and thereby nullifies the effect of fractal morphology. Further, the possibility of gas molecules to diffuse in the material via surface diffusion, Knudsen diffusion (radius of pores in the range of 1-100 nm) and molecular diffusion (radius of pores greater than $100 \mathrm{~nm}$ ) is higher. Fractals offer all three possibilities. The different size of pores (macropores with pore sizes above $50 \mathrm{~nm}$ and mesopores with pore sizes in the range of 2-50 $\mathrm{nm}$ ) are associated with different functions such as delivery, withdrawal reaction canals, and centers for adsorptions [57,69]. For larger pore sizes, rapid gas diffusion rates are observed leading to higher values of sensitivity $[26,89]$. Thus, while the porous continuous network provides a backbone for better and faster charge transport, the unique morphology of fab-fracs offers a better gas-sensor interaction indicated by the fractal dimension.

\section{Conclusion}

Fractals are intriguing structures that are crafted by natural processes and can be fabricated in labs in a controlled environment. Their unique morphologies comprise structures ranging from the nanoscale to the macroscale, where the properties change with the length scales involved. This aspect has been addressed in the present review with focus on gas-sensing properties. While chemical or physical properties of the material may or may not remain the same, a change in geometry and architecture, especially as fractals, can aid in better sensing. Connectivity, exposure to gaseous environment, nanoscale 3D coarsening, and roughness generate many secondary and tertiary adsorption sites that result in better sensitivity. If somehow the interconnectivity can be improved with the help of an artificial electrode, better sensing characteristics can be expected. Thus, fractal geometries show great prospect to be considered as sensor templates, regardless of the used material. The nucleation, growth, and diffusion-limited aggregation of nanoparticles results in the formation of interesting fractal morphologies with high surface-to-volume ratio, high porosity, and interconnectivity within branched structures. Different fractal morphologies with empirically found fractal dimensions of 1.5-1.86 have shown better sensing results. Therefore, studies can be planned to focus on the fractal dimension by theoretical and experimental approaches. Here, lithography techniques can be implemented to write fractals of different fractal dimensions and their response under identical test conditions can be studied. Such structures can also be explored as substrates for surfaceenhanced Raman spectroscopy, which finds applications in areas ranging from food packaging to medical diagnosis. Fractals can also help in mimicking the wound healing process as tissue grows to connect the torn skin across the wound and offer an insight into microfluids as part of wound healing management. Besides application-oriented research the hyperbranched morphologies of fractals, offering high surface area and numer- ous transport channels for gas analytes to reach the electrode of a sensor more quickly, also form a good object of basic science. This review article gives an overview of fractal geometries that have been successfully applied as gas-sensing elements, shows the possibility of growing fab-fracs under controlled lab conditions, and opens a number of ideas that can be taken up by researchers. Indeed, there is little known in the world of fractals and a lot to explore and learn.

\section{Supporting Information}

\section{Supporting Information File 1}

Summary of the fractal structures and their applications. [https://www.beilstein-journals.org/bjnano/content/ supplementary/2190-4286-12-88-S1.pdf]

\section{Acknowledgements}

One of the authors (VK) acknowledges the SIU-JRF awarded by Symbiosis Centre for Research and Innovation, Symbiosis International (Deemed University), Pune, MH, India from Jan 2019-Dec 2020.

\section{Funding}

The research work was supported by SERB, DST (vide grant ECR/2016/001183) and Symbiosis Centre for Research and Innovation (SCRI), Symbiosis International (Deemed University), Pune.

\section{ORCID ${ }^{\circledR}$ iDs}

Vishal Kamathe - https://orcid.org/0000-0003-3823-8850

Rupali Nagar - https://orcid.org/0000-0003-0747-7701

\section{References}

1. Smith, H. O. The London, Texas, School Disaster. The Quarterly of the National Fire Protection Association; 1937; Vol. 30, pp 299-311.

2. Broughton, E. Environ. Health (London, U. K.) 2005, 4, 6. doi:10.1186/1476-069x-4-6

3. 500 on 2 Trains Reported Killed By Soviet Gas Pipeline Explosion. https://www.nytimes.com/1989/06/05/world/500-on-2-trains-reported-kil led-by-soviet-gas-pipeline-explosion.html (accessed Oct 13, 2021).

4. India gas leak: At least 11 dead after Visakhapatnam incident. https://www.bbc.com/news/world-asia-india-52569636 (accessed Aug 17, 2020).

5. Chen, Y.; Zhang, W.; Wu, Q. Sens. Actuators, B 2017, 242, 1216-1226. doi:10.1016/j.snb.2016.09.096

6. Kolmakov, A.; Moskovits, M. Annu. Rev. Mater. Res. 2004, 34, 151-180. doi:10.1146/annurev.matsci.34.040203.112141

7. Korotcenkov, G. Mater. Sci. Eng., B 2007, 139, 1-23. doi:10.1016/j.mseb.2007.01.044

8. Yunusa, Z.; Hamidon, M. N.; Kaiser, A.; Awang, Z. Sens. Transducers J. 2014, 168, 61-75. 
9. Wang, C.; Yin, L.; Zhang, L.; Xiang, D.; Gao, R. Sensors 2010, 10, 2088-2106. doi:10.3390/s100302088

10. Thong, L. V.; Loan, L. T. N.; Van Hieu, N. Sens. Actuators, B 2010, 150, 112-119. doi:10.1016/j.snb.2010.07.033

11. Tonezzer, M. Sens. Actuators, B 2019, 288, 53-59. doi:10.1016/j.snb.2019.02.096

12. Brunet, E.; Maier, T.; Mutinati, G. C.; Steinhauer, S.; Köck, A.; Gspan, C.; Grogger, W. Sens. Actuators, B 2012, 165, 110-118. doi:10.1016/j.snb.2012.02.025

13. Chen, X.; Shen, Y.; Zhang, W.; Zhang, J.; Wei, D.; Lu, R.; Zhu, L.; Li, H.; Shen, Y. Appl. Surf. Sci. 2018, 435, 1096-1104. doi:10.1016/j.apsusc.2017.11.222

14. Liang, J.; Zhao, Y.; Zhu, K.; Guo, J.; Zhou, L. Thin Solid Films 2019, 669, 537-543. doi:10.1016/j.tsf.2018.11.046

15. Yu, H. Y.; Kang, B. H.; Pi, U. H.; Park, C. W.; Choi, S.-Y.; Kim, G. T. Appl. Phys. Lett. 2005, 86, 253102. doi:10.1063/1.1954894

16. Thai, N. X.; Van Duy, N.; Hung, C. M.; Nguyen, H.; Tonezzer, M.; Van Hieu, N.; Hoa, N. D. J. Sci.: Adv. Mater. Devices 2020, 5 , 409-416. doi:10.1016/j.jsamd.2020.05.005

17. Xu, J.; Wang, D.; Qin, L.; Yu, W.; Pan, Q. Sens. Actuators, B 2009, 137, 490-495. doi:10.1016/j.snb.2009.01.011

18. Jagadale, S. B.; Patil, V. L.; Vanalakar, S. A.; Patil, P. S.; Deshmukh, H. P. Ceram. Int. 2018, 44, 3333-3340. doi:10.1016/j.ceramint.2017.11.116

19. Kwon, D.-K.; Porte, Y.; Ko, K. Y.; Kim, H.; Myoung, J.-M. ACS Appl. Mater. Interfaces 2018, 10, 31505-31514. doi:10.1021/acsami.8b13046

20. Dhayal Raj, A.; Pazhanivel, T.; Suresh Kumar, P.; Mangalaraj, D.; Nataraj, D.; Ponpandian, N. Curr. Appl. Phys. 2010, 10, 531-537. doi:10.1016/j.cap.2009.07.015

21. Lou, Z.; Wang, L.; Wang, R.; Fei, T.; Zhang, T. Solid-State Electron. 2012, 76, 91-94. doi:10.1016/j.sse.2012.05.062

22. Li, Z.; Wang, N.; Lin, Z.; Wang, J.; Liu, W.; Sun, K.; Fu, Y. Q.; Wang, Z. ACS Appl. Mater. Interfaces 2016, 8, 20962-20968. doi:10.1021/acsami.6b02893

23. Liu, Y.; Jiao, Y.; Zhang, Z.; Qu, F.; Umar, A.; Wu, X. ACS Appl. Mater. Interfaces 2014, 6, 2174-2184. doi:10.1021/am405301v

24. Liu, J.; Wang, X.; Peng, Q.; Li, Y. Adv. Mater. (Weinheim, Ger.) 2005, 17, 764-767. doi:10.1002/adma.200400993

25. Kolmakov, A.; Klenov, D. O.; Lilach, Y.; Stemmer, S.; Moskovits, M. Nano Lett. 2005, 5, 667-673. doi:10.1021/nl050082v

26. Wang, X.; Wang, Y.; Tian, F.; Liang, H.; Wang, K.; Zhao, X.; Lu, Z.; Jiang, K.; Yang, L.; Lou, X. J. Phys. Chem. C 2015, 119, 15963-15976. doi:10.1021/acs.jpcc.5b01397

27. Zhou, X.; Liu, J.; Wang, C.; Sun, P.; Hu, X.; Li, X.; Shimanoe, K.; Yamazoe, N.; Lu, G. Sens. Actuators, B 2015, 206, 577-583. doi:10.1016/j.snb.2014.09.080

28. Park, H. J.; Choi, N.-J.; Kang, H.; Jung, M. Y.; Park, J. W.; Park, K. H.; Lee, D.-S. Sens. Actuators, B 2014, 203, 282-288. doi:10.1016/j.snb.2014.06.118

29. Nazemi, H.; Joseph, A.; Park, J.; Emadi, A. Sensors 2019, 19, 1285. doi:10.3390/s19061285

30. Lee, J.-H. Sens. Actuators, B 2009, 140, 319-336. doi:10.1016/j.snb.2009.04.026

31. Kim, H.-J.; Lee, J.-H. Sens. Actuators, B 2014, 192, 607-627. doi:10.1016/j.snb.2013.11.005

32. Goldoni, A.; Alijani, V.; Sangaletti, L.; D'Arsiè, L. Electrochim. Acta 2018, 266, 139-150. doi:10.1016/j.electacta.2018.01.170
33. Walker, J. M.; Akbar, S. A.; Morris, P. A. Sens. Actuators, B 2019, 286, 624-640. doi:10.1016/j.snb.2019.01.049

34. Miller, D. R.; Akbar, S. A.; Morris, P. A. Sens. Actuators, B 2014, 204, 250-272. doi:10.1016/j.snb.2014.07.074

35. Franke, M. E.; Koplin, T. J.; Simon, U. Small 2006, 2, 36-50. doi:10.1002/smll.200500261

36. Hung, C. M.; Le, D. T. T.; Van Hieu, N. J. Sci.: Adv. Mater. Devices 2017, 2, 263-285. doi:10.1016/j.jsamd.2017.07.009

37. Dey, A. Mater. Sci. Eng., B 2018, 229, 206-217. doi:10.1016/j.mseb.2017.12.036

38. Sun, D.; Luo, Y.; Debliquy, M.; Zhang, C. Beilstein J. Nanotechnol. 2018, 9, 2832-2844. doi:10.3762/bjnano.9.264

39. Mandelbrot, B. B.; Freeman, W. H. The Fractal Geometry of Nature; Henry Holt and Company, 1983.

40. Yang, T.; Tian, F.; Covington, J. A.; Xu, F.; Xu, Y.; Jiang, A.; Qian, J.; Liu, R.; Wang, Z.; Huang, Y. Chemosensors 2019, 7, 31. doi:10.3390/chemosensors7030031

41. Wang, Z.; Liu, T.; Jiang, L.; Asif, M.; Quu, X.; Yu, Y.; Xiao, F.; Liu, H. ACS Appl. Mater. Interfaces 2019, 11, 32310-32319. doi:10.1021/acsami.9b11726

42. Cao, M.; Liu, T.; Gao, S.; Sun, G.; Wu, X.; Hu, C.; Wang, Z. L. Angew. Chem., Int. Ed. 2005, 44, 4197-4201. doi:10.1002/anie.200500448

43. Chen, Z.; Pan, D.; Zhao, B.; Ding, G.; Jiao, Z.; Wu, M.; Shek, C.-H.; Wu, L. C. M.; Lai, J. K. L. ACS Nano 2010, 4, 1202-1208. doi:10.1021/nn901635f

44. Kandjani, A. E.; Sabri, Y. M.; Field, M. R.; Coyle, V. E.; Smith, R.; Bhargava, S. K. Chem. Mater. 2016, 28, 7919-7927. doi:10.1021/acs.chemmater.6b03537

45. Tran-Phu, T.; Daiyan, R.; Fusco, Z.; Ma, Z.; Abd Rahim, L. R.; Kiy, A.; Kluth, P.; Guo, X.; Zhu, Y.; Chen, H.; Amal, R.; Tricoli, A. J. Mater. Chem. A 2020, 8, 11233-11245. doi:10.1039/d0ta01723j

46. Townsley, M. I. Compr. Physiol. 2012, 2, 675-709. doi:10.1002/cphy.c100081

47. SnowCrystals.com. http://snowcrystals.com (accessed Dec 10, 2020).

48. Ng, T. F.; Teh, G. H. Bull. Geol. Soc. Malays. 2009, 55, 73-79. doi:10.7186/bgsm55200912

49. Fusco, Z.; Rahmani, M.; Bo, R.; Verre, R.; Motta, N.; Käll, M.; Neshev, D.; Tricoli, A. Adv. Mater. (Weinheim, Ger.) 2018, 30 , 1800931. doi:10.1002/adma.201800931

50. Plugotarenko, N. K.; Petrov, V. V.; Ivanetz, V. A.; Smirnov, V. A. Glass Phys. Chem. 2011, 37, 590-595. doi:10.1134/s1087659611060162

51. Sahoo, P.; Sairam, G. M.; Kamruddin, M.; Dash, S.; Tyagi, A. Adv. Mater. (Weinheim, Ger.) 2017, 2, 648-653.

52. Witten, T. A., Jr.; Sander, L. M. Phys. Rev. Lett. 1981, 47, 1400-1403. doi:10.1103/physrevlett.47.1400

53. Vicsek, T. Phys. Rev. Lett. 1984, 53, 2281-2284. doi:10.1103/physrevlett.53.2281

54. Nagar, R.; Teki, R.; Koratkar, N.; Sathe, V. G.; Kanjilal, D.; Mehta, B. R.; Singh, J. P. J. Appl. Phys. 2010, 108, 063519. doi:10.1063/1.3482026

55. Fairbanks, M. S.; McCarthy, D. N.; Scott, S. A.; Brown, S. A.; Taylor, R. P. Nanotechnology 2011, 22, 365304. doi:10.1088/0957-4484/22/36/365304

56. Losa, G. A.; Peretti, V.; Ciotola, F.; Cocchia, N.; De Vico, G. The Use of Fractal Analysis for the Quantification of Oocyte Cytoplasm Morphology. In Fractals in Biology and Medicine; Losa, G. A.; Merlini, D.; Nonnenmacher, T. F.; Weibel, E. R., Eds.; Birkhäuser: Basel, Switzerland, 2005; pp 75-82. doi:10.1007/3-7643-7412-8_7 
57. Gracheva, I. E.; Moshnikov, V. A.; Karpova, S. S.; Maraeva, E. V. J. Phys.: Conf. Ser. 2011, 291, 012017. doi:10.1088/1742-6596/291/1/012017

58. Cai, Y.; Zhang Newby, B.-m. J. Am. Chem. Soc. 2008, 130, 6076-6077. doi:10.1021/ja801438u

59. Maillard, M.; Motte, L.; Ngo, A. T.; Pileni, M. P. J. Phys. Chem. B 2000, 104, 11871-11877. doi:10.1021/jp002605n

60. Deegan, R. D.; Bakajin, O.; Dupont, T. F.; Huber, G.; Nagel, S. R.; Witten, T. A. Nature 1997, 389, 827-829. doi:10.1038/39827

61. Shen, L.; Denner, F.; Morgan, N.; van Wachem, B.; Dini, D. Sci. Adv. 2020, 6, eabb0597. doi:10.1126/sciadv.abb0597

62. Zhao, W.; Li, Y.; Zhang, M.; Chen, J.; Xie, L.; Shi, Q.; Zhu, X. Chem. Eng. J. 2016, 283, 105-113. doi:10.1016/j.cej.2015.07.064

63. Yin, X.-T.; Zhou, W.-D.; Li, J.; Wang, Q.; Wu, F.-Y.; Dastan, D.; Wang, D.; Garmestani, H.; Wang, X.-M.; Țălu, Ş. J. Alloys Compd. 2019, 805, 229-236. doi:10.1016/j.jallcom.2019.07.081

64. Parambhath, V. B.; Nagar, R.; Ramaprabhu, S. Langmuir 2012, 28 , 7826-7833. doi:10.1021/la301232r

65. Im, J.; Shin, H.; Jang, H.; Kim, H.; Choi, M. Nat. Commun. 2014, 5, 3370. doi: $10.1038 /$ ncomms 4370

66. Mohamed, S. H. J. Alloys Compd. 2012, 510, 119-124. doi:10.1016/j.jallcom.2011.09.006

67. Zhang, Y.; Li, D.; Qin, L.; Zhao, P.; Liu, F.; Chuai, X.; Sun, P.; Liang, X.; Gao, Y.; Sun, Y.; Lu, G. Sens. Actuators, B 2018, 255 , 2944-2951. doi:10.1016/j.snb.2017.09.115

68. Kante, I.; Devers, T.; Harba, R.; Andreazza-Vignolle, C.; Andreazza, P. Microelectron. J. 2005, 36, 639-643. doi:10.1016/j.mejo.2005.04.036

69. Moshnikov, V. A.; Gracheva, I. E.; An'chkov, M. G. Glass Phys. Chem. 2011, 37, 485-495. doi:10.1134/s1087659611050063

70. Grachova, I. E.; Maksimov, A. I.; Moshnikov, V. A. J. Surf. Invest.: X-Ray, Synchrotron Neutron Tech. 2009, 3, 761-768. doi:10.1134/s1027451009050176

71. Phadungdhitidhada, S.; Thanasanvorakun, S.; Mangkorntong, P.; Choopun, S.; Mangkorntong, N.; Wongratanaphisan, D. Curr. Appl. Phys. 2011, 11, 1368-1373. doi:10.1016/j.cap.2011.04.007

72. Jeun, J.-H.; Kim, D.-H.; Hong, S.-H. Mater. Lett. 2013, 105, 58-61. doi:10.1016/j.matlet.2013.04.036

73. Sabri, Y. M.; Kandjani, A. E.; Rashid, S. S. A. A. H.; Harrison, C. J.; Ippolito, S. J.; Bhargava, S. K. Sens. Actuators, B 2018, 275, 215-222. doi:10.1016/j.snb.2018.08.059

74. Bailly, G.; Rossignol, J.; de Fonseca, B.; Pribetich, P.; Stuerga, D. Procedia Eng. 2015, 120, 764-768. doi:10.1016/j.proeng.2015.08.812

75. Fan, F.; Feng, Y.; Tang, P.; Chen, A.; Luo, R.; Li, D. Ind. Eng. Chem. Res. 2014, 53, 12737-12743. doi:10.1021/ie501825t

76. Liu, X.; Zhang, J.; Yang, T.; Wang, L.; Kang, Y.; Wang, S.; Wu, S. Powder Technol. 2012, 217, 238-244. doi:10.1016/j.powtec.2011.10.032

77.Zhang, N.; Yu, K.; Li, Q.; Zhu, Z. Q.; Wan, Q. J. Appl. Phys. 2008, 103, 104305. doi:10.1063/1.2924430

78. Simon, I.; Savitsky, A.; Mülhaupt, R.; Pankov, V.; Janiak, C. Beilstein J. Nanotechnol. 2021, 12, 343-353. doi:10.3762/bjnano.12.28

79. Qin, Y.; Wang, Z.; Liu, D.; Wang, K. Mater. Lett. 2017, 207, 29-32. doi:10.1016/j.matlet.2017.07.042

80. Xiao, B.; Wang, D.; Wang, F.; Zhao, Q.; Zhai, C.; Zhang, M. Ceram. Int. 2017, 43, 8183-8189. doi:10.1016/j.ceramint.2017.03.144

81. Zhao, Y.; Xie, Y.; Zhu, X.; Yan, S.; Wang, S. Chem. - Eur. J. 2008, 14, 1601-1606. doi:10.1002/chem.200701053

82. Bai, S.; Sun, L.; Sun, J.; Han, J.; Zhang, K.; Li, Q.; Luo, R.; Li, D.; Chen, A. J. Colloid Interface Sci. 2021, 587, 183-191. doi:10.1016/j.jcis.2020.10.113
83. Guo, W.; Ma, J.; Pang, G.; Wei, C.; Zheng, W. J. Mater. Chem. A 2014, 2, 1032-1038. doi:10.1039/c3ta12938a

84. Pang, H.; Gao, F.; Chen, Q.; Liu, R.; Lu, Q. Dalton Trans. 2012, 41 , 5862-5868. doi:10.1039/c2dt12494g

85. Wang, J.; Wei, L.; Zhang, L.; Zhang, J.; Wei, H.; Jiang, C.; Zhang, Y. J. Mater. Chem. 2012, 22, 20038-20047. doi:10.1039/c2jm34192a

86. Zhao, Q.; Chuai, M.; Xiao, B.; Yang, T.; Luo, Y.; Zhang, M. New J. Chem. 2015, 39, 7873-7878. doi:10.1039/c5nj01523e

87. Ji, H.; Zeng, W.; Li, Y. Nanoscale 2019, 11, 22664-22684. doi:10.1039/c9nr07699a

88. Wang, M.; Hou, T.; Shen, Z.; Zhao, X.; Ji, H. Sens. Actuators, B 2019, 292, 171-179. doi:10.1016/j.snb.2019.04.124

89. Sakai, G.; Matsunaga, N.; Shimanoe, K.; Yamazoe, N. Sens. Actuators, B 2001, 80, 125-131. doi:10.1016/s0925-4005(01)00890-5

90. Yamazoe, N.; Fuchigami, J.; Kishikawa, M.; Seiyama, T. Surf. Sci. 1979, 86, 335-344. doi:10.1016/0039-6028(79)90411-4

91. Deng, Y. Semiconducting Metal Oxides for Gas Sensing; Springer Singapore: Singapore, 2019. doi:10.1007/978-981-13-5853-1

92. Seal, S.; Shukla, S. JOM 2002, 54, 35-38. doi:10.1007/bf02709091

\section{License and Terms}

This is an Open Access article under the terms of the Creative Commons Attribution License (https://creativecommons.org/licenses/by/4.0). Please note that the reuse, redistribution and reproduction in particular requires that the author(s) and source are credited and that individual graphics may be subject to special legal provisions.

The license is subject to the Beilstein Journal of Nanotechnology terms and conditions: (https://www.beilstein-journals.org/bjnano/terms)

The definitive version of this article is the electronic one which can be found at: https://doi.org/10.3762/bjnano.12.88 